\title{
3D printing of tissue engineering scaffolds: a focus on vascular regeneration
}

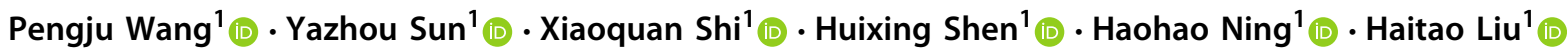

Received: 23 August 2020 / Accepted: 24 October 2020 / Published online: 4 January 2021

(c) Zhejiang University Press 2021

\begin{abstract}
Tissue engineering is an emerging means for resolving the problems of tissue repair and organ replacement in regenerative medicine. Insufficient supply of nutrients and oxygen to cells in large-scale tissues has led to the demand to prepare blood vessels. Scaffold-based tissue engineering approaches are effective methods to form new blood vessel tissues. The demand for blood vessels prompts systematic research on fabrication strategies of vascular scaffolds for tissue engineering. Recent advances in 3D printing have facilitated fabrication of vascular scaffolds, contributing to broad prospects for tissue vascularization. This review presents state of the art on modeling methods, print materials and preparation processes for fabrication of vascular scaffolds, and discusses the advantages and application fields of each method. Specially, significance and importance of scaffold-based tissue engineering for vascular regeneration are emphasized. Print materials and preparation processes are discussed in detail. And a focus is placed on preparation processes based on 3D printing technologies and traditional manufacturing technologies including casting, electrospinning, and Lego-like construction. And related studies are exemplified. Transformation of vascular scaffolds to clinical application is discussed. Also, four trends of 3D printing of tissue engineering vascular scaffolds are presented, including machine learning, near-infrared photopolymerization, 4D printing, and combination of self-assembly and 3D printing-based methods.
\end{abstract}

Keywords Tissue engineering $\cdot 3 \mathrm{D}$ printing $\cdot$ Vascular scaffolds $\cdot$ Print materials $\cdot$ Modeling methods

\section{Introduction}

One of the main challenges in preparation of large-size tissues is the supply of nutrients to cells [1]. Usually diffusion-driven nutrients and oxygen cannot be adequately obtained by cells [2]. Blood vessels provide channels for nutrient transport and metabolism of tissues and organs [3]. And vascular-related diseases are one of the main causes of death. Vascular regeneration is defined as regeneration of blood vessels to restore the structure and function of damaged tissues and organs, which is a promising method to treat these diseases $[4,5]$. Current methods for vascular regeneration consist of implantation of tissue-engineered vascular grafts, placement of stents, surgical bypass grafting, angioplasty and implantation of non-biodegradable conduits [6]. Vessels

\section{Haitao Liu}

hthit@hit.edu.cn

1 Department of Mechanical Manufacturing and Automation, School of Mechatronics Engineering, Harbin Institute of Technology, Harbin 150001, China rebuilding is commonly involved in vascular regeneration, aiming to fabricate biologically functional and structural vessels from endothelial cells, smooth muscle cells, stem cells, bioactive molecules, biomaterials and corresponding cell aggregates or spheroids [7]. Methods for vessels rebuilding include fabrication of vascular scaffolds, decellularization of vessels, fabrication of self-assembly vascular grafts and subsequent vessel maturation processes such as the utilization of vessel-reactors and introduction of culture additives [6, 8]. Demand for vascular grafts increases year by year. However, vascular tissues with a given shape and function cannot be achieved by conventional autologous implantation and allograft transplantation $[9,10]$. Scaffold-based tissue engineering technology provides solutions to this problem [11]. Vascular scaffolds are reconstructed by modeling and preparation to guide cell adhesion and proliferation and formation of new blood vessels [12]. And scaffolds are completely degraded after angiogenesis [13].

Physiological structures of blood vessels in human bodies are complex, usually with heterogeneous, porous, and permeable properties [11]. Traditional manufacturing technology 
may fail to recapitulate the vascular physiology. For example, the resolution of micromolding is low [14], and the formed scaffolds sometimes lack cell binding sites [15]. Moreover, the cross section of flow channels of scaffolds prepared by soft lithography is usually rectangular [16]. Besides, there are a lack of control on blood vessel geometry and organization by self-assembly [2] and a lack of cell infiltration in scaffolds by decellularized methods $[17,18]$. 3D printing technology is an additive manufacturing technology, providing a tool for recapitulation of the vascular physiology. Based on a specified path, discrete units of print materials can be stacked into $3 \mathrm{D}$ structures by $3 \mathrm{D}$ printing. With the rapid development of 3D printing technology, complex vascular scaffolds can be prepared by determining print materials, improving printing devices and optimizing printing processes. Print materials are cell-friendly, biocompatible, and degradable [19-21]. Hydrogel materials, such as alginate hydrogel [22], gelatin [23], and methylated gelatin (GelMA) [24], are widely used in $3 \mathrm{D}$ printing due to their good crosslinking and biocompatible properties. Different print materials match corresponding $3 \mathrm{D}$ printing processes.

In view of the importance and urgent needs of blood vessels as well as the development of $3 \mathrm{D}$ printing technology, the topic of 3D printing of vascular scaffolds for tissue engineering has become a hot research direction. Increasing researchers from engineering, materials science, and life sciences start and devote to make contributions in this field. A recent Web of Science search for either the topic of 3D printing and tissue engineering and scaffold and artery/arteriole/capillary/vein/venule, or the topic of 3D printing and tissue engineering and scaffold and blood vessel/vascular tissue engineering excluding the topic of artery/arteriole/capillary/vein/venule, returns over 150,000 publications in each of the latest three years. And the number of articles published has increased year by year (Fig. 1).

Overall, 3D printing technology has been used in scaffoldbased tissue engineering. Several reviews have been reported with vascular tissue engineering strategies based on $3 \mathrm{D}$ printing [25-28]. However, to our knowledge, there is a lack of a systematic introduction about feasibility of the 3D printed scaffolds for vascular regeneration, modeling, print materials, and preparation processes to this specific field. The present study focuses on existing modeling methods and commonly used 3D printing technologies for fabrication of vascular scaffolds, and systematically discusses the feasibility, modeling methods, print materials, and preparation methods involved in the whole process of fabrication of vascular scaffolds. Print materials and 3D printing technologies are discussed in detail, and related technologies including casting, electrospinning and Lego-like construction are used as complement to illustrate methods of 3D printing of vascular scaffolds. Specially, a comparison between scaffold-based and scaffold-free approaches is presented to highlight the

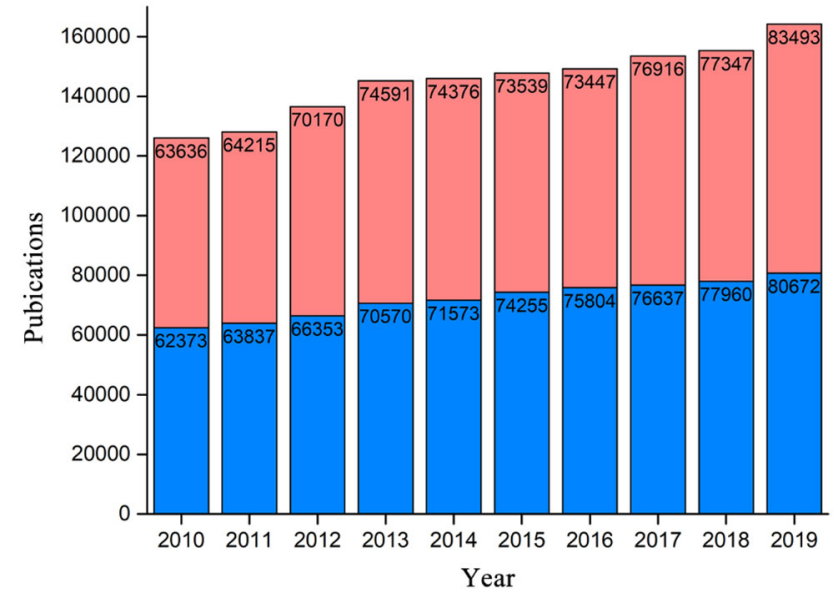

Artery/Arteriole/Capillary/Vein/Venule

Tissue engineering + Blood vessel/Vascular tissue engineering

Fig. 1 The statistics data from Web of Science for either the topic of 3D printing and tissue engineering and scaffold and artery/arteriole/capillary/vein/venule, or the topic of 3D printing and tissue engineering and scaffold and blood vessel/vascular tissue engineering excluding the topic of artery/arteriole/capillary/vein/venule. Data were retrieved in the past 10 years

significance of scaffold-based tissue engineering for vasculatures. And transformation of vascular scaffolds to clinical productivity is also discussed. Future directions for 3D printing of vascular scaffolds are also presented.

\section{Significance and importance of scaffold-based tissue engineering}

Usual substitutes to tissues and organs are autograft and allograft. However, frequent symptoms of disease recurrence and immunological rejection limit the extensive clinical application of these technologies. The emergence of tissue engineering technology makes an amazing supplement to these substitutes. This is due to the conquerable defects of insufficient donors and immune response. There are usually two methods for vascular tissue engineering: scaffold-based and scaffold-free approaches [6]. Compared to scaffold-free methods (e.g., decellularization methods [29]), scaffoldbased strategy can direct cell colonization and proliferation through a pathway [12]. As we all know, 3D printing technology has made significant progress in the past decades. Based on the idea of discrete stacking, scaffolds with complex features (e.g., graded materials, multiscale porous structures) are easily manufactured using 3D printing technology. Reasonably, increasing researches about biofabrication are adopted with the interdisciplinary technology of 3D printing and scaffold-based tissue engineering [25-27]. And a series of gratifying advances are achieved in vascular tissue engineering [11]. But many directions have been focused on in vitro 
vascular tissue engineering [25]. A possible meaningful innovation is angiogenesis and vasculogenesis in vivo [30-32]. The following discussion reviews the interesting and important subject of feasibility of 3D printed vascular scaffolds to form new blood vessel tissues in vivo. On the basis, scaffold-based vascular tissue engineering is introduced. And a comparison between the scaffold-based and scaffold-free approaches is presented to emphasize the advantages of $3 \mathrm{D}$ printing of vascular scaffolds for vasculatures.

\section{Feasibility of 3D printed scaffolds to form new blood vessel tissues in vivo}

Generally, cellular composition of blood vessel tissues includes endothelial cells, smooth muscle cells and fibroblasts [8], distributed in blood vessels from inside to outside, respectively. Different distributions of the three types of cells contribute to diversified physiology structures of blood vessels. As shown in Fig. 2, blood vessels are composed of artery, arteriole, capillary, vein, and venule. Both arteries and veins are made up of tunica externa, tunica media, tunica intima, and endothelium. In contrast, structures of venules and arterioles are relatively simple. A similar structure between them is endothelium. Arterioles also contain tunica media and basal lamina, and tunica externa is a composition of venules. Capillaries are constituted of fenestrated and continuous structures, comprising endothelial cells and basal lamina. Among them, the range of diameter of capillaries is $5-10 \mu \mathrm{m}$, and vein is $20-3000 \mu \mathrm{m}$, and diameter of arteries is $30-2500 \mu \mathrm{m}$ [11]. Due to the prevalence of vascular diseases and the shortage of vascular organs, blood vessels are investigated to make a solution to meet demand. Tissue engineering and organ engineering are promising technologies to solve the shortages of donor organs. The regeneration of vascular networks is essential for successful engineered tissues or organs. Decellularization methods, using decellularized extracellular matrix as inducible biomaterials, were proven to be an effective way to form new blood vessels in vivo [29]. Although decellularization methods have been used on different types of tissues or organs, they have been limited to fabrication of simple tissues. Besides, limited sources and batch-to-batch variability also hinder the application of this method [11]. Are there other technologies to achieve the same function? Scaffold-based tissue engineering may be an alternative solution. 3D printing technology advances the field of tissue engineering. To supplement and enrich the approaches of vascularization in vivo, it is necessary to discuss the feasibility of scaffold-based methods.

Almost all blood vessels are of hierarchical structures [8]. It is feasible to prepare a graded hierarchical structure by $3 \mathrm{D}$ printing. Scaffold-based fabrication provides rational spatial distribution for vascular cells by providing growth microenvironments for cell propagation and guiding cell adhesion, localization, and colonization [11, 25, 28]. Besides, stimulation cues regulate cell growth [33]. The biochemical cues can be obtained by surface coating of scaffolds or products after degradation [34, 35]. The biophysical cues (e.g., hardness, strain, hydrostatic pressure, shear stress, cyclic stress, and surface topology) can be given directly by scaffolds or with the help of external fields [36,37]. And there are some aspects that need to be characterized to ensure the feasible scaffolds for cell growth: i) evaluate shape and aperture of scaffolds by microscopy techniques [38]; ii) determine the porosity by the liquid replacement method [39]; iii) evaluate the mechanical properties including elastic modulus, breaking strength, and compliance and so on through the corresponding experiments [40]; iv) evaluate the degradability by calculating the percentage of their residual mass after degradation [19]; v) evaluate the biocompatibility by combining microscopy techniques and histological staining [41]. After that, formation of blood vessels is achieved by cell culture with the appropriate regulation of biochemical and biophysical cues. Subsequently, scaffolds are fully degraded in vivo [13]. The ultimate goal is to implant vascular scaffolds in bodies. However, difficult anastomosis between engineered blood vessels by decellularization methods and corresponding blood vessels in bodies is often encountered in animal experiments and clinical cases $[15,42]$, because hierarchical structures of blood vessels make it difficult for artificial vascular grafts to match vascular anatomy. This problem leads to poor patency of blood vessels and some complications in bodies [4]. It is feasible to create a 3D printed scaffold to fit vascular anatomy to improve host vasculature to sprout or facilitate anastomosis between the engineered blood vessels and corresponding host vasculatures. Specially, biochemical cues about target vascular anastomosis can be integrated in scaffolds. With the advancement of precision medicine and imaging technology, precise implantation is expected to be realized.

While scaffold-based tissue engineering methods are theoretically feasible and reasonable, there are still some insurmountable problems limited by current 3D printing technology. The smaller and more various the blood vessel diameter, the higher the requirements for $3 \mathrm{D}$ printing processes and equipment. Usually, integrated technologies of 3D printing and other technologies ((e.g., casting, electrospinning, Lego-like construction, post-treatment technology) contribute to the preparation of complex and high-precision scaffolds. It is envisaged that fabrication of micron-sized vascular scaffolds is quite easy in future. Another problem is the damage generated from surgical resection to transplantation. Minimally invasive treatment is a trend in clinical surgery. In recent years, increased intraoperative printing and intravital printing have been reported [43, 44]. Using these technologies, a scaffold in vivo can be directly formed by injection of bioinks or biomaterial inks followed by $3 \mathrm{D}$ printing. Overall, scaffold-based methods are at pre-experimental 


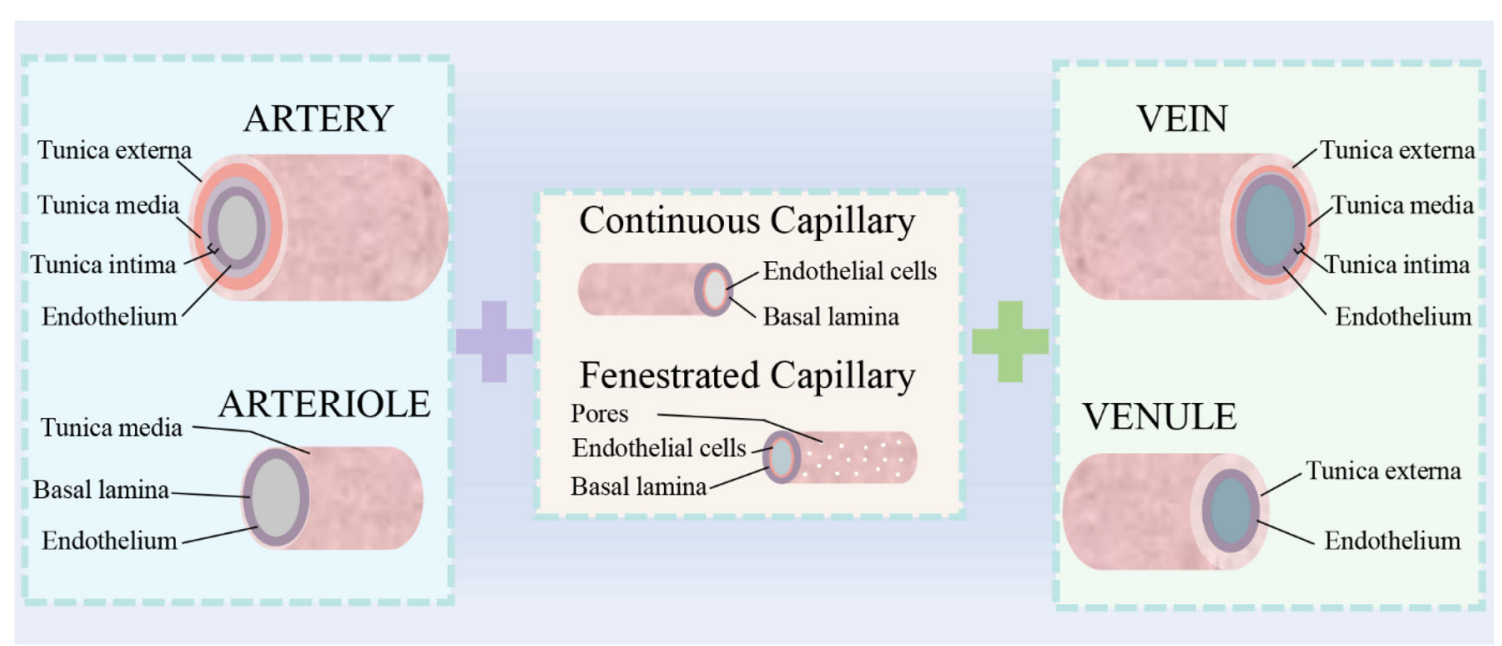

Fig. 2 Schematic diagram of organization and hierarchical structures of blood vessels. Blood vessels consist of artery, arteriole, capillary, vein, and venule that span the scale from a few microns to a few millimeters

stages. With the expansion of biomaterials, the development of 3D printing-based rapid prototyping methods, the precise positioning of image recognition technology and further investigation of vascular physiology and anatomy, 3D printed scaffolds to form new blood vessel tissues in vivo are expected to achieve widely clinical application.

\section{Scaffold-based tissue engineering to create a scaffold for a vasculature}

As we discussed above, it is feasible to fabricate vasculature scaffolds by $3 \mathrm{D}$ printing to form new blood vessel tissues in vivo. However, it is not easy to create a scaffold for a vasculature. Fabrication strategies of scaffold-based tissue engineering for vascular regeneration by $3 \mathrm{D}$ printing are shown in Fig. 3 [11]. First, vascular scaffold models are created through parametric modeling or microcomputed tomography (micro-CT)/magnetic resonance imaging (MRI)-based $3 \mathrm{D}$ reconstruction [45-47]. Subsequently, based on biomaterial inks or bioinks, scaffolds are prepared by combining print materials [20] and 3D printing-based technologies (e.g., integrated technologies of 3D printing and casting or electrospinning or Lego-like construction) [48-50]. As a proof of concept, properties of scaffolds (e.g., interconnectivity, configuration, biomechanical and biochemical properties) are characterized to confirm functional requirements [36]. The point to emphasize here is that material properties of stiffness, compliance, biocompatibility, and degradability play a key role in blood vessel formation [33]. After addition of bioactive substances for cell growth, tissue formation is guided by prepared scaffolds, accompanying with suitable degradation of scaffolds in vitro and in vivo [51, 52].

Most approaches of scaffold-based vascular tissue engineering involve vascular cells [25]. During this process, two interaction modes are presented between vascular cells and scaffolds. One is scaffolds load with cells, and the other is scaffolds with cell seeding $[22,53]$. As a saying goes, "every coin has two sides". The mode of cell-laden scaffolds presents a better spatial positioning for cells than scaffolds with cell seeding [54]. But limited materials [20] and harsh preparation processes [48-50] prevent the popularization of this method. Moreover, scaffolds with cell seeding contribute to the diversity of new blood vessel tissues. Another method is to directly implant a cell-free scaffold into a body to induce the formation of blood vessels [17]. More strict requirements on cell-free scaffolds are required. For blood vessel formation, a common method is in vitro culture followed by surgical implantation in bodies [11]. In particular, bioreactors [51, 52] help cell culture and tissue formation. A difficult problem of this scheme is the fusion between implanted organs and human tissues after implantation [15, 42]. And the immune response $[4,5]$ in bodies is waiting to be resolved after scaffold implantation.

This tissue engineering strategy is faced with many challenges. To begin with, xenogeneic cells are not friendly enough for bodies, but insufficient source of autologous vascular cells limits widespread clinical applications [9, 10]. Secondly, bioinks are required to be friendly to both printing processes and 3D cell culture [21]. Moreover, the forming accuracy of scaffolds and the influence of forming processes on cells are necessary for in-depth investigations. Besides, there are also problems with cell culture and tissue formation processes $[11,13,55,56]$. What are the optimal culture conditions for vascular cell proliferation, migration, differentiation, and tissue formation? How to regulate the growth of vascular cells after preparation of scaffolds? How to match the degradation rate of scaffolds with the rate of formation of new vascular tissues? How to make new blood vessels 
Fig. 3 Schematic diagram showing the fabrication strategies of scaffold-based tissue engineering by 3D printing for vascular regeneration. A preparation process of vascular scaffolds includes four stages before cell culture: 3D modeling, preparation of print materials, manufacturing processes, and characterization of scaffolds. 3D printing-based manufacturing processes can be used for fabrication of complex vascular scaffolds

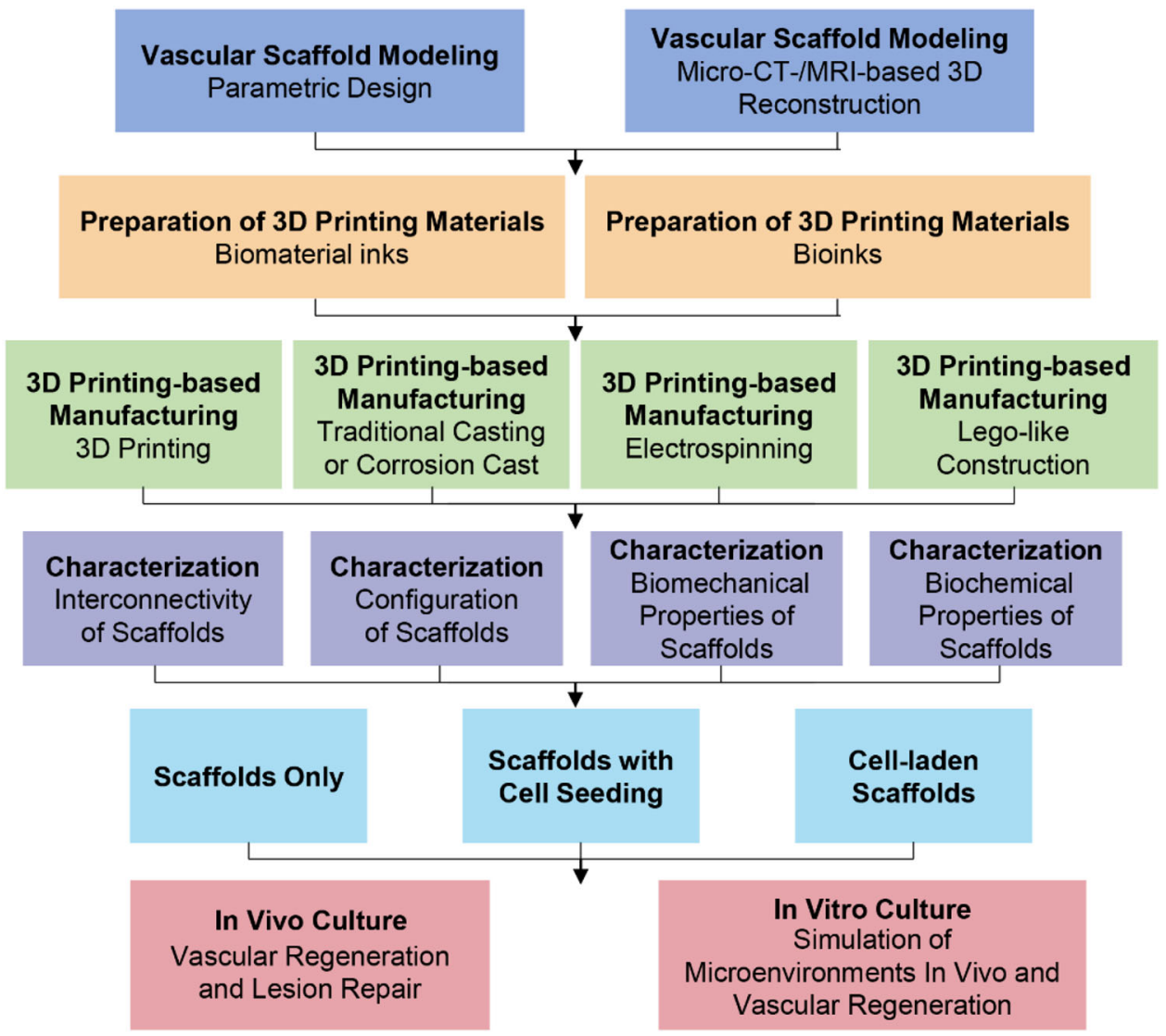

integrate with the body to form connected blood vessel networks to promote metabolism and nutrient delivery? And this tissue engineering strategy involves many engineering technologies and life science technologies. To engage in this field requires a wide range of knowledge. Sometimes, urgent surgical rehearsals and transplant operations require rapid preparation of personalized vascular grafts. Standardized and generalized preparing methods and the evaluation criteria regarding scaffolds and new blood vessels need to be established to benefit researchers from different fields.

\section{Comparison between the scaffold-based and scaffold-free approaches}

The mechanism of scaffold-free approaches is based on the bottom-up self-assembly of cell sheets, cell spheroids and tissue strands [1]. Cells and growth factors are placed on matrix materials, or injected into tissues in situ. Tissues are formed by fusion and maturation of cell sheets or cell spheroids or tissue strands, accompanied by the deposition of corresponding extracellular matrix (ECM). Among them, preparations of blood vessels are usually based on the assembly of cell spheroids and cell sheets [6]. The cell sheets were formed by culturing a monolayer of cells on the surface of petri dishes coated with materials. And building blocks of cell spheroids were prepared in anti-adhesion wells to form vascularized tissues [57]. Compared with cell sheets, simple formation of cell spheroids contributes to more methods of creation. Usually, there are three methods for the formation, including microfluidics, spheroids on matrices, and hanging drop techniques [57]. Cell spheroids can be directly formed on patterned matrices [58]. In microfluidic methods, cell spheroids are formed by fabricating channels with different structures to manipulate fluids [59]. Besides, hanging-drop approach by inverting cell-seeding plates is another feasible method [60]. Both matrices and microchannels can be fabricated by $3 \mathrm{D}$ printing-based methods $[1,61]$. Although scaffoldfree approaches are also advancing, there are inescapable aspects in vascularized tissue engineering, where scaffoldbased methods are better than the scaffold-free methods.

As we introduced, 3D positioning of cells in hierarchical structures directly affects the formation of new blood vessels. However, it is difficult to place cells in appropriated position of cell spheroids, cell sheets or tissue strands by scaffold-free methods, leading to poor simulation of hierarchical distribution of cells. 3D printing-based technologies overcome the defect by loading cells in bioinks or fabricating regulatable adhesion sites on scaffolds. Moreover, although the interaction between cells in scaffold-free approaches provides analogical physiological conditions compared to 
complex tissues, these physiological environments are generally uncontrollable and highly variable, leading to unattainable standardized mass production. In contrast, controllable growth microenvironments for cell growth can be created by 3D printing-based integrated technologies. For instance, a smooth inner surface for improving blood compatibility and formation of endothelial cell monolayers was prepared by 3D printing technologies [62]. This builds the prerequisite for customized preparation of artificial grafts fitting physiological properties of blood vessels.

And there is doubt about sufficient mechanical properties of tissue structures provided by the scaffold-free approaches. Moreover, the mechanical properties of building blocks of cell spheroids may cause cell damage during cell assembly. Using scaffold-based approaches, various biophysical and biochemical properties of scaffolds can be created. This is due to the wide range of material sources and diverse processes. Besides, in botany, plant growth is guided by support rods in some cases. Speaking of cell-free scaffolds, were they also easy for blood cells to climb and grow? Gao et al. [63] confirmed this idea by cell seeding of multi-scale scaffolds. They found that cells easily adhered to thin fibers and maintained high proliferation, and then cells bridged across the pores and migrated to thick fibers. It is feasible to regulate the climbing of cells on 3D printing-based scaffolds by determining the appropriate fiber thickness, pore size, and mechanical properties. In contrast, scaffold-free methods are weak in guiding cell climb because scaffolds for guided cell growth are not involved. The formation of tissues depends on self-assembly of cells, and the process has a certain randomness.

\section{Modeling methods for vascular scaffolds}

Scaffolds serve as carriers for vascular cells and affect the formation of vascular tissues [13]. The morphology and size of different structural layers of blood vessels are multiscale, and the sizes of macroscopic and microstructural layers are significantly different [28]. Precise replication of original vascular structures can produce optimized vascularized networks. Due to the limitation of manufacturing technologies, current vascular scaffolds can only be prepared on the micron-level [30]. In detail, a vascular scaffold is prepared by creating 3D models with stereolithography (STL) file format, which are then imported into 3D printers for manufacturing [7]. Up to now, many methods are proposed to precisely model $3 \mathrm{D}$ vascular scaffolds such as modeling by algorithm [45] and micro-CT-based 3D reconstruction [46]. Common design approaches of vascular scaffolds involve extraction of original structural parameters and direct design by 3D modeling software [45-47]. Modeling software can be used to design simple vascular scaffolds, such as cylindrical structures and bifurcated Y-shaped vascular structures [45]. Compared with simple structures, algorithms for parametric design are usually needed to model complex structures [64]. Structural parameters can be directly extracted by reverse engineering [46] to reconstruct 3D models, which not only provide a reference standard for parametric design of structures, but also avoid tedious modeling theories and design processes. In this chapter, modeling methods are divided into two categories including parametric design and reverse engineering.

\section{Parametric design}

Parametric design is based on algorithms to generate 3D models with given parameters. It's a conventional modeling method using computer-aided design (CAD), which has been widely used in CAD modeling, since lots of models can be rapidly constructed by this method. Although shapes of scaffolds can be achieved by additive manufacturing technology, it is difficult to accurately design microstructures closing to natural vascular scaffolds due to the inherent heterogeneity and complexity of blood vessels. Based on the above reasons, researches in vascular scaffold modeling are currently focused on construction of structures to functionally meet the anatomical and biological characteristics of vascular tissues. However, this method is time consuming and sometimes requires manual operations. To design scaffolds with specific external shapes and controllable internal structures, many modeling methods, such as the secondary development method of CAD software, have been proposed in current researches. Building models using available modeling software and programming languages are popular way of modeling. For example, a triply periodic minimal surface (TPMS) is defined as a surface with periodicity in X, Y, and $\mathrm{Z}$ directions of Cartesian coordinate systems. Main types of TPMS surfaces include P, G, and D surfaces. Each surface is described by a mathematical function. Kadkhodapour et al. [65] constructed models using a TPMS-based modeling method. The $\mathrm{P}$ and $\mathrm{D}$ surfaces of models with different volume fractions were designed, respectively (Fig. 4Ai). However, there is a disadvantage of function-based modeling methods like this. The obtained models are usually regular and simple, leading to inaccurate simulation of heterogeneous vascular scaffolds.

To overcome the shortcomings, Kriegman et al. [66] designed reconfigurable structures using artificial intelligence (AI). Based on multiple iterations, structural building blocks were created by an evolutionary algorithm. This algorithm automatically optimized structural design to achieve different functions for cells (Fig. 4Aii). Compared to the former method, the latter algorithm is evolvable and contributes to reasonable bionic designs of functional macro-micro structures. However, due to the limitations of computer mem- 


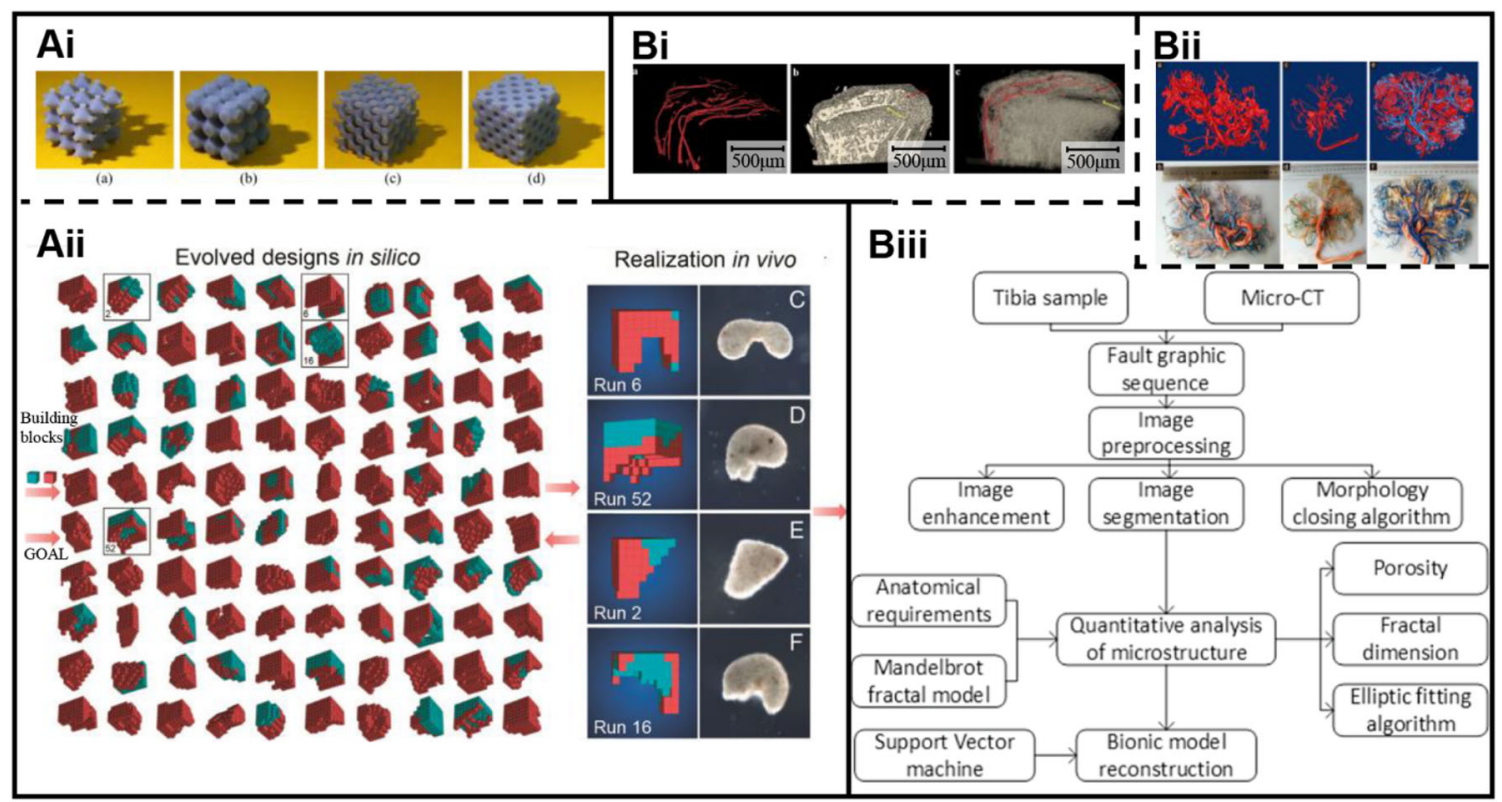

Fig. 4 Modeling methods of vascular scaffolds: A Algorithms-based parametric modeling: Ai Modeling by a TPMS algorithm to build models with different volume fractions. Reproduced with permission [65]. Copyright 2014, Elsevier. Aii Modeling by an AI-based evolutionary algorithm to design reconfigurable structures. Reproduced with permission [66]. Copyright 2020, National Academy of Sciences. B Reverse engineering-based modeling to create models of blood vessels:

ory and configuration, it is almost impossible to model sub-micron vascular structures by only machine learning methods because even simple calculations of modeling require millions of voxel units, and $10^{\wedge} 9$ to $10^{\wedge} 10$ or more voxel units are required for moderately complex calculations. The combination of traditional parametric design and machine learning may be an effective way. That is, macromodels are modeled using parametric modeling methods, and micro- and local models with high bionic requirements are modeled by AI-based evolutionary algorithms. Both approaches provide convenience, especially for engineering and technical personnel. The clinical need for vascular implants is urgent. In this context, the ability to quickly build same or similar models in batches is necessary. And standardized and generalized algorithms make it possible. Besides, in computer-aided manufacturing (CAM), expertise for modeling excluding algorithm designs and compilation of data files are rarely required. A common method in CAM systems is to input parameters in a data interaction system of software, and subsequently the model is obtained by running the algorithms. Although there are few standardized algorithms for blood vessel modeling, as one of the most promising approaches, parametric modeling is expected to be widely used.
Bi 3D reconstruction by micro-CT scanning. Reproduced with permission [67]. Copyright 2016, Springer Nature. Bii 3D reconstruction by MRI scanning. Reproduced with permission [47]. Copyright 2016, John Wiley and Sons. Biii Modeling by CT scanning and parametric modeling to build complex microstructures. Reproduced with permission [64]. Copyright 2020, Springer Nature

\section{Reverse engineering}

In contrast to parametric design, reverse engineering methods have advantages for personalized modeling of vascular scaffolds. As we know, personalized vascular grafts are also an indispensable aspect of clinical practice for tissue repair and replacement. Although reverse engineering methods are not often used for large quantities of modeling of structures with similar characteristics, 3D structures of vascular scaffolds can be non-destructively extracted by reverse engineering. And the reconstructed 3D models have good anatomical matching with the original blood vessels when the accuracy of scanning layer thickness is high enough. For vascular scaffold modeling, micro-CT-based and MRI-based reverse engineering methods have been reported [46, 47]. A usual procedure of reconstructing 3D models of vascular scaffolds is as follows: first, imaging data of vascular scaffolds are collected by scanning; then the data format is converted to a DICOM format file; finally, models of scaffolds are reconstructed by 3D software such as Mimic by adjusting the extraction range of gray values. $\mathrm{Xu}$ et al. [67] created 3D models of blood vessels in rabbit endplates using MicroCT data. This entailed, first vertebral endplates and vessel models were created using Otsu method to determine the threshold value. Next, superimposed models were obtained 
by merging vertebral endplate models with vessel models through Boolean operations (Fig. 4Bi). In this way, 3D models involved vascular scaffolds can be easily built. Wang et al. [47] reconstructed human placental vascular networks using MRI data. The authors compared the effects of different perfusion fluids on imaging placental vessels and vascular $3 \mathrm{D}$ reconstruction, and found that the addition of Gd-DTPA in immersion fluids enabled the vessels of placentas to be accurate reconstructed by MRI (Fig. 4Bii). The choice of perfusion fluids is the key to affecting clarity of MRI imaging. Moreover, morphological parameters of structures can be accurately extracted by reverse engineering, which can be used for parametric modeling.

Our team [64] proposed a new modeling method based on CT scanning. First, 2D tomographic image sequences of microstructures were acquired by CT scanning. To accurately obtain structure parameters, image sequences were then processed by a designed image processing algorithm. Subsequently, structure parameters such as the perimeter and area of pores were obtained through a designed algorithm for edge detection. We then fitted the pores by designing an ellipse-based fitting algorithm. Next, the fractal dimension of image sequences was calculated by the method of island. On the basis, using support vector machine and structural risk minimization principles, a mapping database theory about the pores of CT images and porosity, fractal dimension and Poisson's ratios were proposed. Finally, a concept of 3D modeling based on AI was proposed by us, as shown in Fig. 4Biii. This method is a combination of reverse engineering and parametric design to reconstruct 3D models. The advantages of accurate extraction of structural parameters by reverse engineering, and rapid and automated parametric modeling by parametric design, are applied. Although there are several types of blood vessels with complex hierarchical structures, anatomical parameters of blood vessels such as inner diameter, porosity, thickness and elastic modulus can be correlated with design parameters. From our perspectives, even if there are few visible reports, the topic is an interesting and promising research area in tissue engineering.

\section{Pros and cons: modeling methods for vascular scaffolds}

In general, modeling of vascular scaffolds involves parametric modeling and reverse engineering. Each method has advantages and disadvantages. Compared with reverse engineering methods, modeling by algorithms-based parametric modeling can quickly and automatically build scaffold models. However, for preparation of personalized and bionic vascular scaffolds, structures with high anatomical compatibility of human blood vessels can be reconstructed by reverse engineering-based modeling methods. 3D shapes of vascular scaffolds are determined by the corresponding anatomical parameters such as length, area, volume, and angle. Anatomical parameters are obtained by measurement and calculation. Micro-CT scanning and MRI are two available methods to obtain the parameters. Then, reconstruction of 3D models can be achieved by obtaining structural parameters and then parametric modeling or scanning the structures to obtain points cloud data to directly reconstruct. However, due to the limitation of manufacturing processes, structures of blood vessels usually cannot be fully reflected in the structural parameters obtained in the prepared structures. How to build functionalized blood vessel grafts? What parameters need to be considered in the modeling of scaffolds? Simplifying the 3D models may be an effective method. But how to ignore the structural parameters with extremely small dimensions is still a problem to be considered in parametric design and reverse engineering. Although there is no uniform standard, it is necessary to quantify evaluation criteria. There are some aspects that need to be characterized to ensure the feasibility of the two designs in vivo post manufacture: (i) predict elastic modulus and dilation and constriction of scaffolds by finite element analysis and numerical simulation of fluid mechanics [68]; (ii) predict oxygen and nutrient content of scaffolds with channels by numerical simulation [2]; (iii) match the porosity and aperture of the models with the structure of original blood vessels through measurement software and other methods [69]; (iv) enable the models of the two designs to fit for the corresponding physiological structures [70].

Blood vessels extend into virtually most tissues of bodies. Bone tissues, lung, heart, and other tissues almost all contain blood vessels. In modeling of these organizations, both hard tissues and soft tissues are usually involved. For the modeling of other tissue scaffolds superimposed with vascular scaffolds, based on parametric design or reverse engineering, hard tissue scaffolds and vascular scaffolds are modeled, respectively. And then reconstructed models are obtained by performing Boolean operations between hard tissue scaffolds and vascular scaffolds in 3D modeling software. The aspects of superior 3D modeling algorithms of vascular scaffolds, accurate micro-CT/MRI imaging, and reduction of manual operations are the main research domains about modeling methods. In addition, expertise of CT/MRI is unfamiliar for engineering staff. In contrast, algorithm theories are difficult to be mastered by medical personnel. Interdisciplinary cooperation and communication are indispensable means to model a vascular scaffold. Moreover, rapid and automated and accurate scaffold modeling is the development trend of vascular scaffold modeling in future. To this end, developing new design methods and building a database between vascular morphological characteristics and scaffold attributes may be a solution. 


\section{D printing materials for vascular scaffolds}

A material is a composition of a structure. Scaffolds are prepared by materials and processes. Properties and components of materials narrow down the range of 3D printing-based preparation processes. Print materials with good rheological and biological properties are one of the important factors for successful preparations of vascular scaffolds. As the raw materials for 3D printing, print materials directly affect the printability and biophysical and biochemical properties of vascular scaffolds [25]. Printability directly affects the accuracy of printed structures. Biophysical properties affected by printing materials are 3D morphology, stiffness, and forces. Biochemical properties affected are degradability and biocompatibility. Both biophysical properties and biochemical properties may regulate cell differentiation and tissue formation. Degradability implies print materials can be eliminated by microenvironments in vivo or in vitro over time. The match between the degradation rate of scaffolds and the rate of angiogenesis greatly affects the structural integrity of new blood vessels. Biocompatibility indicates print materials cause appropriate host response, such as cell-friendly interaction. Therefore, the choice of print materials is critical for the formation of new blood vessels. Discussing the following three points will help determine the print materials and contribute to the diversity of preparation methods. What kinds of printing materials are there? How to prepare the desired materials as natural materials may not be suitable for certain situations? What auxiliary materials and processes of print materials usually involved to fabricate a bionic vascular scaffold?

\section{Types of print materials}

Basically, print materials include bioinks and biomaterial inks. As demarcated by Groll et al. [20], cells are an essential component of bioinks, while biomaterial inks are cell-free biomaterials for 3D printing. Hereby cell-loaded scaffolds can be prepared based on print materials loaded with vascular cells. Vascular cells can also be seeded on printed scaffolds to fabricate vascular tissues. The source of vascular cells can be the differentiation of mesenchymal stem cells or the culture of endothelial cells, smooth muscle cells and fibroblasts. Compared with biomaterial inks, the types of bioinks are limited, because cell survival rate during the forming processes must be guaranteed. Of course, the forming processes, causing bioinks to suffer high temperature or high stress or high-intensity ultraviolet rays and other harsh environments, are excluded during 3D printing. In contrast, in strategies of printing of biomaterial inks and cell adhesion, the available selection of materials and processes is wider. Biomaterials, such as fibronectin, were reported as a surface-adsorbed precoating for scaffolds [71]. But cells are not easy to locate in
3D space. At cell culture stages, scaffold materials affect the proliferation, migration, differentiation of vascular cells, and further vascularity [33].

Blood vessels are a soft tissue structure. Usually, bioceramics and metal materials are not suitable for vascular scaffolds in tissue engineering. General types of biomaterials for vascular scaffolds include natural materials, synthetic materials, composite materials, and decellularized extracellular matrix (dECM) [21]. Natural materials (e.g., alginate, collagen, silk fibroin, hyaluronic acid, matrigel, gelatin) are of good biocompatibility and economy. Synthetic materials (e.g., polycaprolactone, polylactic acid, polyethylene glycol diacrylate, hydroxyapatite, GelMA) have superiority in the properties of individuality and good physic-chemical properties. The emerging biomaterial, $\mathrm{dECM}$, is a new type of biomaterial providing excellent ecological niches for cells. And growth factors, enzymes, and biomacromolecules for cell growth can be supplied by dECM. For example, using cell-laden dECM bioinks, Jang et al. [72] fabricated complex scaffolds by 3D printing to repair cardiac defects. And the effect was ideal, because vascularization was promoted and the function of the heart was improved. Usual hyaluronic acid (HA) hydrogel is also a component of animal ECM. In addition, composite materials are also important components in vascular scaffolds, which are optimized combination of material components mentioned above with different properties. Sun et al. [35] engineered magnesium ion-based compositive materials. The degradation of the scaffold led to the release of magnesium ions, thereby promoting cell proliferation and gene expression. The combination of materials expands the limited source of print materials. In particular, compared with other materials, strength and diversity in composite materials are improved.

Among them, hydrogels are probably one of the most frequently used biomaterials in preparation of vascular scaffolds and tissue formation. This is due to the good biocompatibility and crosslinking properties of hydrogels. After printing, hydrogel structures are cured by crosslinking reactions to maintain integral structures. Temperature-sensitive, ion-sensitive, and light-sensitive hydrogels were reported to fabricated complex vascular networks [21]. Gelatin, alginate hydrogel, and GelMA and HA are four common hydrogels used in the preparation of vascular scaffolds. Gelatin and GelMA can be cured using temperature-sensitive crosslinking. The crosslinking mechanism is presented in Fig. 5A [73]. GelMA and Methacrylic hyaluronic acid (HAMA) can be cured by irreversible photocrosslinking. And alginate hydrogels can be cured by the reversible physical crosslinking between calcium ion and alginate. These crosslinking mechanisms provide the possibility for preparations of complex multi-scale porous scaffolds. 


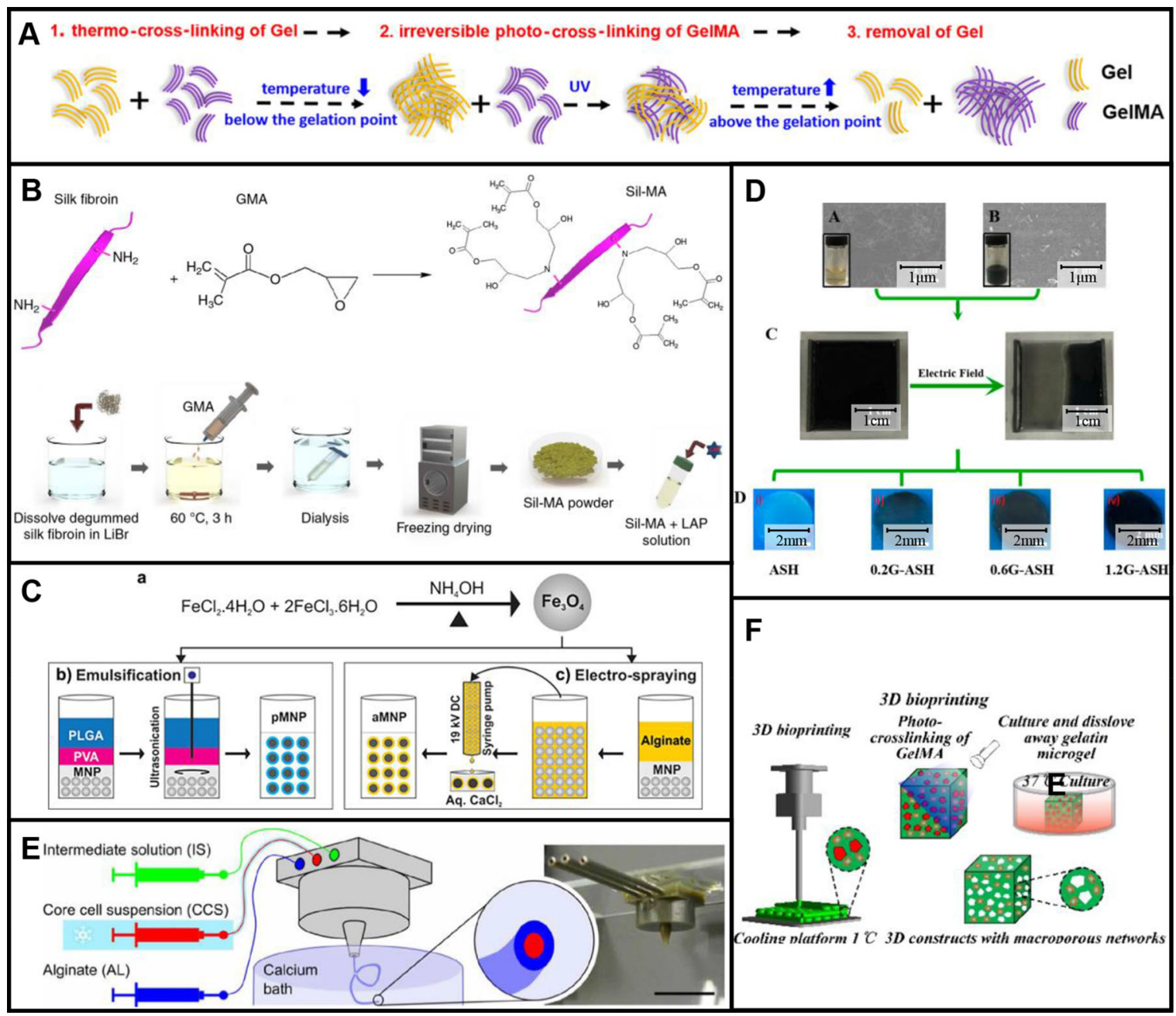

Fig. 5 Crosslinking processes of common hydrogels and preparations of modified SF, functionalized MNPs and silk-graphene hydrogels: A Schematic diagram of a crosslinking process of Gelatin and GelMA. Reproduced with permission [73]. Copyright 2019, American Chemical Society. B Preparation of SF bioink by modification of SF molecules. Reproduced with permission [74]. Copyright 2018, Kim et al. C Preparation of functionalized MNPs with PLGA by co-precipitation and ultrasonication, and preparation of functionalized MNPs by co-

\section{Preparation of print materials}

Gelatin and alginate are natural hydrogels, and GelMA is prepared by synthesis. For instance, based on gelatin powders and methacrylic anhydride, Hsieh et al. [24] synthesized GelMA. In this process, gelatin powders were first completely dissolved in Dulbecco's phosphate-buffered saline (DPBS) by stirring. Methacrylic anhydride was then added to the DPBS solution, which was dialyzed and freeze-dried to prepare GelMA. In this method, GelMA with diverse degrees of substitution can be synthesized. Silk fibroin (SF) biomaterial fabricated with glycidyl methacrylate (GMA) was prepared by the modification of SF molecules with GMA precipitation and electro-spraying. Reproduced with permission [76]. Copyright 2017, John Wiley and Sons. D Preparation of silk-graphene hydrogels by electric fields. Reproduced with permission [75]. Copyright 2018, American Chemical Society. E Ionic crosslinking of alginate hydrogels. Reproduced with permission [80]. Copyright 2019, Andrique et al. F Thermal crosslinking of Gelatin and GelMA and photocrosslinking of GelMA. Reproduced with permission [23]. Copyright 2020, Springer Nature

[74], as shown in Fig. 5B. Silk fibroin was first dissolved in lithium bromide. And then GMA was added into the solution. Finally, modified SF was prepared by dialysis and freeze drying. To achieve a specific function of vascular scaffolds, materials such as graphene [75] and magnetic nanoparticles [76] are used as additives to form composite materials. Jeon et al. [76] prepared surface-functionalized magnetic nanoparticles (MNPs) using iron oxide nanoparticles, poly (lactic-co-glycolic acid) (PLGA), and sodium alginate. The surface functionalized MNPs using PLGA (pMNP) were prepared by co-precipitation and ultrasonication. The surface functionalized MNPs using alginate (aMNP) were prepared by co-precipitation and electro-spraying (Fig. 5C). Intra- 
cellular delivery of surface-functionalized scaffolds was enhanced by magnetic fields.

Overall, synthesis processes for materials involve solution preparation and mixing, stirring, dissolution, dialysis, freeze-drying, volatilization, precipitation, and sonication/ultrasonication. To be clear, a process of solution preparation is the dissolution of solute materials in a solvent to make a solution with a certain concentration and then mixing of different solutions with a certain ratio. Stirring is to make the solutions fully mixed and accelerate the reaction processes. Ultrasonication is used to change the size of the solutes or the synthesized materials. These processes of dialysis, freeze-drying, volatilization, and precipitation are to remove the solvents to extract synthetic materials. Except for the synthesis of biomaterials with different biochemical properties, the preparation of materials with different size (such as aperture) is also a research aspect. Liu et al. [77] prepared a $20-\mu \mathrm{m}$-long collagen microfiber-embedded hydrogel. The collagen fibers with different sizes were fabricated by thermal crosslinking, homogenization, and sonication of collagen sponges. Cell adhesion is improved by collagen fibers mediated by integrin molecules. Intermittent between fibers promotes cell migration and growth. A structure of porous materials is usually achieved through the mixing of soluble materials (such as sodium chloride, sucrose, and gelatin) and original biomaterials, followed by dissolving the sacrificial materials. Lei et al. [23] prepared GelMA with mesoscale pore networks. The gelled gelatin was crushed into gelatin microgel. After the mixing of microgel and GelMA, the mesoporous GelMA was prepared by dissolving the gelatin. Pore sizes of blood vessel walls are very small, leading to the difficult fabrication by $3 \mathrm{D}$ printing. This method of processes is so important because nutrients and oxygen need to pass through the pores of blood vessel walls to ensure penetration for cells. For fabrication of bionic vascular scaffolds, chemical and structural properties of print materials need to be well integrated.

\section{Auxiliary materials and processes for fabrication of vascular scaffolds}

During fabrications of vascular scaffolds, auxiliary processes are used as a complement to the forming processes. There are three aspects usually involved using auxiliary materials: (i) chemical modification [78] and physical modification [75] of printing materials; (ii) printing processes [22, 23, 79]; and (iii) post-treatment processes [34, 71]. Some materials such as methacrylate, GMA, and magnesium chloride hexahydrate are utilized for chemical modification [35, 78]. For example, photocrosslinkable properties of SF biomaterial for UV curing were achieved by its chemical modification using GMA [78]. And a bioactive material was prepared by the incorporation of magnesium ion into printing materials using complexation interaction [35]. For physical modification, auxiliary materials are usually added into print materials. And materials such as graphene are added to hydrogels to achieve specific functions of vascular scaffolds. Wang et al. [75] developed silk-graphene hybrid hydrogels with silk fibroin (SF) and graphene. Graphene nanosheets were generated and encapsulated using the exfoliating agent of SF nanofibers. Because graphene materials are conductive. By the migration of graphene sheets under electrical fields, the phase of hybrid hydrogels was changed (Fig. 5D), and their aligned patterns were formed. After determining the graphene content, different biochemical and physical cues including graphene, aligned topography, and mechanical stiffness can be tailored into vascular scaffolds.

During printing processes of vascular scaffolds, materials such as photoabsorbers, calcium chloride and support materials have also been reported [22, 23, 79]. Grigoryan and co-workers [79] designed a photoabsorber for PEGbased hydrogels. By adding tartrazine as the photoabsorber, the accuracy of printed vascular scaffolds was significantly improved compared to traditional UV curing methods. And based on the diffusion of calcium ions, sodium alginate can be crosslinked [22]. Andrique et al. [80] used a calcium bath to crosslink the extruded solution of alginate hydrogel, as shown in Fig. 5E. This method can be used to prepare spatial structures in suspension baths. And sacrificial materials (e.g., gelatin, sodium chloride and sucrose) are usually used as the support materials because of their printability and solubility [23, 81, 82]. Gelatin as the material to construct support structures for the preparation of mesoscale pore networks was reported by Lei et al. [23]. Their work was based on the reversibility of temperature-sensitive crosslinking characteristics of gelatin and the irreversibility of photosensitive crosslinking characteristics of GelMA (Fig. 5F). Subsequently, sacrificial materials are liquefied when a dissolving solution is introduced or the temperature is changed.

Besides, auxiliary materials are involved in post-treatment processes. Coated materials such as poly-L-lysine [34] were reported. These materials improve the properties of scaffolds and contribute to their functionalization. Specially, surface coating is useful for improving the hydrophilicity of hydrophobic scaffolds. To sum up, although some auxiliary materials are reported, there is still a demand of special auxiliary materials for the preparation of customized vascular scaffolds. Moreover, compared to other auxiliary materials, bioactive materials are good for cell growth. Future researches on these materials need to be focused. 


\section{Preparation methods of vascular scaffolds by 3D printing}

Traditional subtractive technologies have difficulty in manufacturing complex structures. For instance, to fabricate porous structures, Wang et al. [83] reported a preparation method for tubular and cylindrical scaffolds using a mold-based casting technology. Based on two-step phase separation, porous molds were prepared, and the corresponding porous scaffolds were obtained. Interconnected porous structures were closed to anatomical requirements of vascular scaffolds. The pore size of scaffolds can be changed by adjusting polymer mixing ratio to obtain molds with different pore structures. But pore positions of the prepared scaffold structures cannot be determined, and an accurate polymer mixing ratio is required. Recently, in combination with $3 \mathrm{D}$ printing technologies, three common methods for fabrication of vascular scaffolds have been reported: integrated technology of casting and 3D printing, integrated technology of electrospinning and 3D printing, and integrated technology of Lego-like construction and 3D printing.

\section{D printing}

3D printing commonly used for fabrication of vascular scaffolds involves extrusion-based 3D printing, inkjet 3D printing, and ultraviolet (UV)-assisted 3D printing [25]. Extrusion-based 3D printing [54] is the most common printing method, but limited in printing high-resolution structures. Inkjet 3D printing [84] overcomes these problems, but limited in printing high concentration cells because of small diameter nozzles. Although the damage to cells is found, UV-assisted 3D printing [27] is still a common method for high-precision printing of structures. And to prepare highly idealized vascular scaffolds, both 3D printing devices and forming processes, especially nozzles, printing parameters, printing paths and rheological properties, are investigated.

\section{Extrusion-based 3D printing}

There are two types of extrusion-based 3D printing: directly printing on floor and printing in support bath [26]. Structures are formed by nozzle movements and material extrusion through pressure applying. Development of extrusion-based 3D printing devices has been focused in recent years. Attalla et al. [3] fabricated a device with tri-layered hollow channels to prepare heterogeneous vascular scaffolds. The needles of three nozzles were connected by a microfluidic channel and were used to guide bioinks to the center of corresponding channels (Fig. 6A). By loading various materials in different nozzles and adjusting the size of needles mentioned above, heterogeneous and hollow structures were easily fabricated. This method is simple except for the preparation of branched perfusion networks. A similar approach is using a single nozzle integrated with multiple microfluidic channels. For example, coaxial nozzle-assisted 3D printing was reported to fabricate vascular scaffolds with built-in microchannels [85-91]. Gao et al. [53] placed alginate in the outer flow channel and calcium chloride in the inner flow channel (Fig. 6B). Based on the crosslinking properties between calcium ions and alginate, structures with built-in microchannels were prepared. However, this method requires precise control of flow rate and calcium ion concentration. Later, their group used the same device to print a vascular scaffold with microchannels [22]. In this way, endothelial cells, smooth muscle cells, and fibroblasts were printed step by step, respectively. These vascular scaffolds were of sufficient mechanical strength. In contrast to coaxial nozzle, a nozzle of multiple microchannels converged into one microchannel were reported by Zhao's group [92] to fabricate heterogeneous structures. Multiple inks were created by controlling extrusion flow rates of different materials. To facilitate thorough mixing of different inks, air flow was exerted at the nozzle outlet. Based on the principle of multi-material composition mixing through microchannels, nozzles for 3D printing were further investigated. Skylar-Scott et al. [93] fabricated multinozzle 3D printheads for efficient preparation of voxelated structures with heterogeneous materials. Extrusion pressure of each material was controlled by voltage, and heterogeneous structures were formed by seamless switch of print materials (Fig. 6C). This method has advantages in preparing complex vascular scaffolds and mass production because of multinozzle nozzles. To ensure the integrity of structures and 3D printing in space, 3D printing in suspension baths was investigated, as shown in Fig. 6D. Melo et al. [94] reported a 3D printing process based on a suspension bath. First, cell-loaded fibrinogen was crosslinked by suspension bath through extrusion-based 3D printing. Next, the support bath was crosslinked by UV light. After the above two steps, cells were directly adhered to microfluidic channels following printing paths. Using the difference in crosslinking properties between print materials and suspension baths, vascular scaffolds can be prepared by dissolving print materials or removing suspension materials. Another method to fabricate vascular scaffolds was with the help of a rotating tubular model (Fig. 6E). The rotating model was driven by a stepper motor. Based on the rotating model, vascular scaffolds were prepared by extrusion-based 3D printing followed removal of the model [95]. But this method is difficult for the preparation of complex scaffolds.

For extrusion-based 3D printing, improving printing devices is conducive to forming heterogeneous structures, and optimizing printing processes helps improve printing accuracy. Sharp corners and uneven spacing between adjacent print paths are the main factors affecting printing accuracy. An optimized print path was developed by Jin et al. 


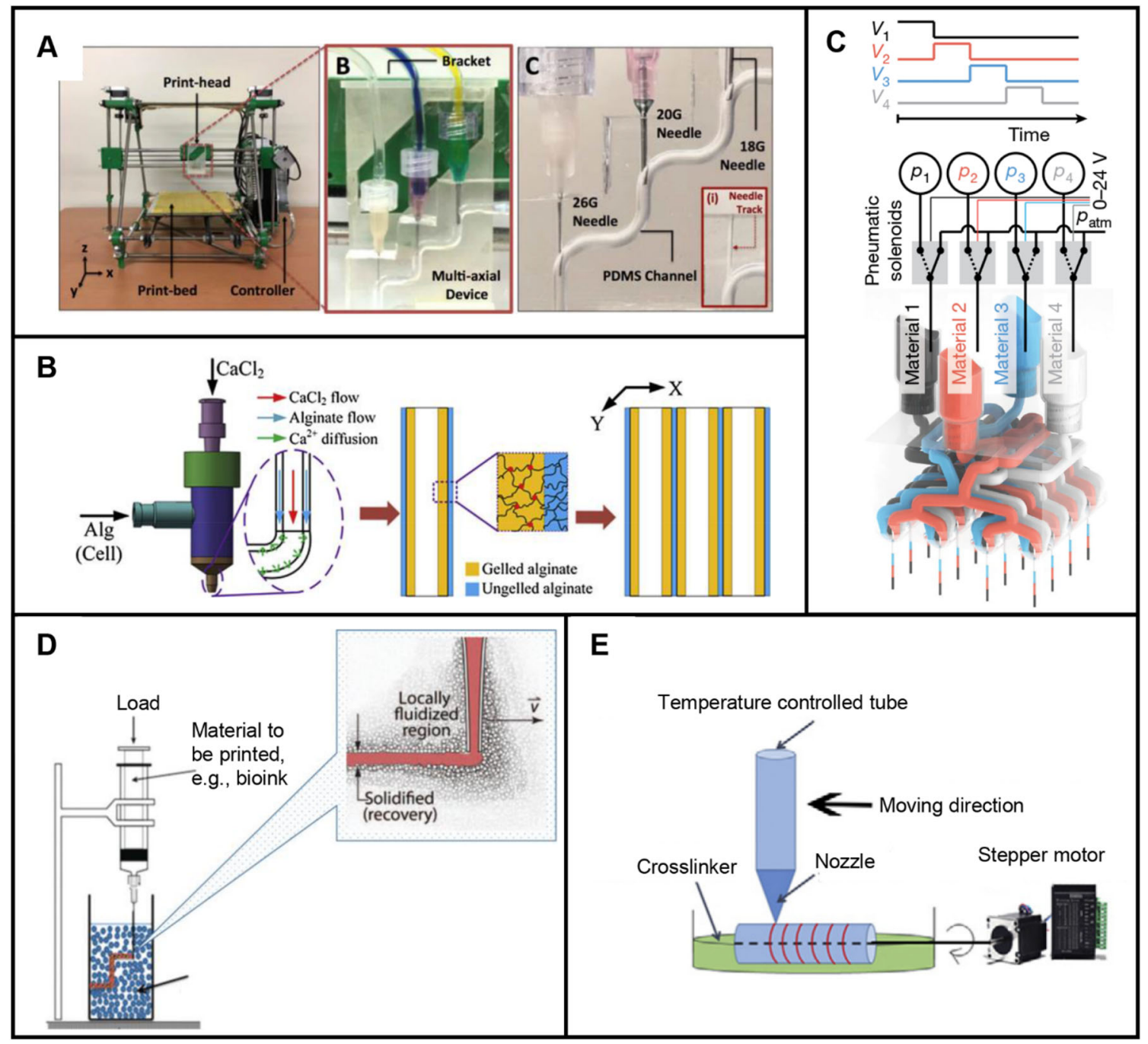

Fig. 6 Extrusion-based 3D printing for scaffold-based vascular tissue engineering: A Preparation of vascular scaffolds with tri-layered hollow channels by an extrusion-based 3D printing device. Reproduced with permission [3]. Copyright 2018, IOP Publishing. B Preparation of vascular scaffolds with built-in microchannels by coaxial nozzle-assisted 3D printing. Reproduced with permission [53]. Copyright 2015, Elsevier. C Preparation of voxelated structures with heterogeneous materials

[96] to improve structural quality. The number of corners was reduced by applying a designed implicit algorithm. Following this, uniform spacings were achieved by optimizing the location of points on the path. This method improved structural quality. However, for 3D printing of structures with arbitrary shapes, path planning needs to be further researched. Effects of the addition of nanoclay materials and standoff distance on forming quality of structures were investigated to improve print fidelity [97]. The authors used a high-speed camera to capture the shape of droplets at the nozzle. Here the extrusion property of $\mathrm{N}$-isopropylacrylamide was significantly improved and die swelling was eliminated by an extrusion-based multinozzle bioprinter. Reproduced with permission [93]. Copyright 2019, Springer Nature. D Preparation of vascular scaffolds by extrusion-based 3D printing in suspension baths. Reproduced with permission [26]. Copyright 2020, McCormack et al. E Preparation of vascular scaffolds by extrusion-based 3D printing on a stepper motor-driving rotating tubular model. Reproduced with permission [95]. Copyright 2020, Elsevier

after adding nanoclay. And then the standoff distance was optimized by designing a mathematical model. This method used nanoclay as a rheology modifier to improve printing accuracy, but gravity and rheological properties were ignored in the designed model of standoff distance. In addition, the accuracy of structures was significantly improved through the optimization of process parameters, such as printing speed, extrusion pressure, and nozzle diameter [3, 48, 73]. 


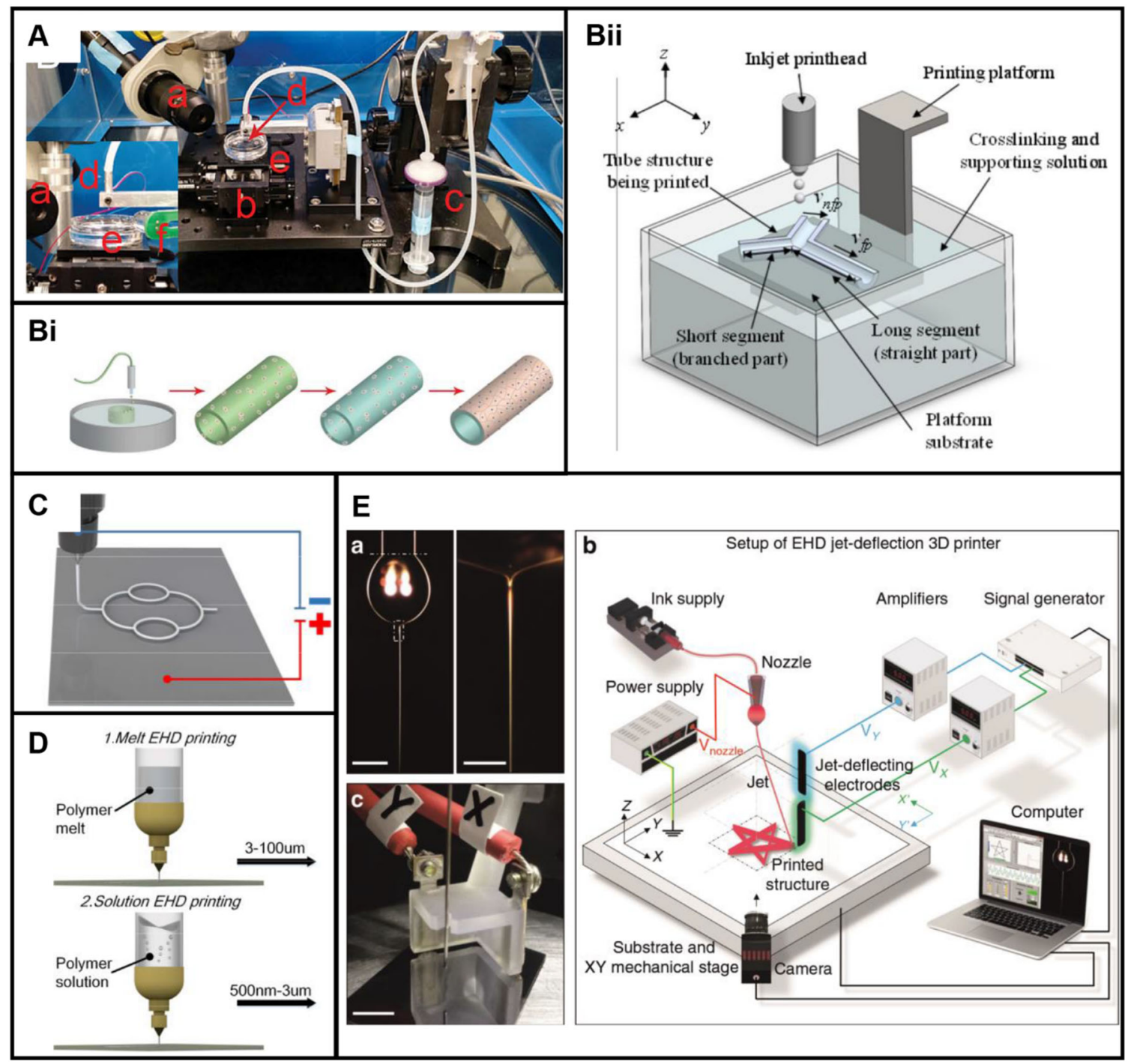

Fig. 7 Inkjet 3D printing for scaffold-based vascular tissue engineering: A An inkjet 3D printing device. Reproduced with permission [84]. Copyright 2017, Elsevier. B Inkjet 3D printing processes: Bi Schematic diagram of an inkjet 3D printing process. Reproduced with permission [84]. Copyright 2017, Elsevier. Bii Schematic diagram of a buoyancyenabled inkjet 3D printing method. Reproduced with permission [98]. Copyright 2018, American Society of Mechanical Engineers ASME. C
Schematic diagram of EHD 3D printing devices. Reproduced with permission [99]. Copyright 2020, IOP Publishing. D Sketch of two kinds of EHD 3D printing with ranges of diameter of $500 \mathrm{~nm}-100 \mu \mathrm{m}$. Reproduced with permission [99]. Copyright 2020, IOP Publishing. E An improved EHD 3D printing device with additional electrodes. Reproduced with permission [100]. Copyright 2020, Liashenko et al

\section{Inkjet 3D printing}

In inkjet 3D printing, droplets are sprayed through small diameter nozzles to selectively deposit. Most power of actuators is thermal or piezoelectric. Based on multi-component materials, structures with different colors can also be printed by inkjet 3D printing. As shown in Fig. 7A, camera, motorized stage, syringe, nozzle, crosslinker bath and LED light are the components of an inkjet 3D printing device. Hewes et al. [84] prepared a vascular scaffold by inkjet 3D printing with a printing path of circular patterns (Fig. 7Bi). The endothelial cell-loaded bioink excluding cells consisted of alginate and fibrinogen. However, it is difficult to prepare complex structures by this method. As a method for improvement of processes, freeform inkjet 3D printing was proposed by Christensen et al. [98] $\mathrm{CaCl}_{2}$ solution was used as a support bath, providing buoyant force for the droplets (Fig. 7Bii). However, the problem of fusion of droplets is still confused. And, based on the mode of droplet ejection, print speeds of scaffolds by traditional inkjet 3D printing are low, and auxiliary curing devices are usually required. 
As a kind of emerging inkjet 3D printing technology, electrohydrodynamic (EHD) 3D printing for scaffolds is widely developed in recent years. The principle of EHD 3D printing is based on the ejection of droplets driven by a high-voltage electric field, which is generated between the nozzles and the substrate (Fig. 7C). Classified by print materials, types of EHD 3D printing include melt EHD 3D printing and solution EHD 3D printing [99] as shown in Fig. 7D. Polymers solution and melt are popular materials used in inkjet 3D printing. Precision of melt EHD printing is from $3 \mu \mathrm{m}$ to100 $\mu \mathrm{m}$. In contrast, precision of solution EHD 3D printing ranges from $500 \mathrm{~nm}$ to $3 \mu \mathrm{m}$. Whatever scaffolds of capillaries with micron diameters or centimeter-sized arteries and veins, almost all accuracy of diameter can be theoretically achieved by EHD 3D printing. But this technique existing inherent flaws are waiting to be improved. Usually a print martial by ejecting cannot be accurately collected by the slow-speed printing platforms. To improve the accuracy of structures by EHD 3D printing, additional electrodes were added [100]. The authors added a deflection electrode between the nozzle and mechanical platform to compensate for the lag effect of the movement speed of the mechanical platform. By jet deflecting using an added electric field, sub-micron structures were prepared at three to four times the printing speed of the original technology (Fig. 7E). Yet there is no uniform standard for how to add deflection electrodes. To improve the accuracy and printing efficiency, this is a research point, but not limited to this aspect. The improvement of inkjet $3 \mathrm{D}$ printing devices is reported less than extrusion-based $3 \mathrm{D}$ printing. And more researches are focused on printing processes or combining with other printing methods. This is due to the slow forming speed and lag effect of printing platforms in inkjet 3D printing. In addition, combined technologies of inkjet 3D printing and other 3D printing are reported to prepare multi-scale vascular scaffolds. Gao et al. [63] reported a direct writing system based on EHD 3D printing and fused deposition molding (FDM) technology. In this instance, the authors quickly switched the modes of EHD 3D printing and FDM 3D printing by switching electric fields. Generally, the printing accuracy of inkjet $3 \mathrm{D}$ printing is usually higher than FDM 3D printing. Based on inkjet 3D printing for microscale and FDM 3D printing for macro-scale, multi-scale scaffolds were prepared. However, the effect of electric fields in EHD 3D printing on vascular cells remains to be studied. Most of the current researches focus on the preparation of scaffolds with cell-free print materials. The trend of EHD 3D printing in the short term is conceived as an auxiliary method for preparation of scaffolds.

\section{UV-assisted 3D printing}

During UV-curing processes, print materials are cured by UV irradiating. There are two main applications of UV-curing technology: soft lithography and UV-assisted 3D printing technology. Soft lithography technology is often used for fabrication of simple structures and microchannels. For instance, based on the reverse pattern from an image mask, Du et al. [16] prepared a dimethylsiloxane scaffold with the aid of photoresist layers. A wafer was coated with photoresist, and a designed mask was added between the light source and patterns. After UV light irradiating and casting, a mold was obtained. In this method, the process is simple, but image masks require extra design. For fabrication of complex structures such as vascular scaffolds, UV-assisted 3D printing technology compared to soft lithography is more commonly used. The principle of UV-assisted 3D printing is not complicated. Based on scanning paths, UV light is irradiated to the surface of a photosensitive material to cure a specific area, and then the 3D printing platform is moved with a certain distance of slice thickness to cure another layer of the materials based on the original cured layer, and finally a 3D structure is fabricated.

In contrast to extrusion-based 3D printing and inkjet 3D printing, higher precision of structures is achieved by UVassisted 3D printing. More and more preparation methods using UV-assisted 3D printing were reported [27]. The printing process was optimized by Li et al. [101] On the basis of the printability of a pre-crosslinked bioink and the precise control of UV light irradiating, a new continuous UV-assisted 3D printing method was proposed by $\mathrm{Li}$ et al. [101]. The printing accuracy and printing speed were improved by the optimization strategy. Like inkjet 3D printing, researches on UV-assisted 3D printing reported focus not only on the forming processes but also on printing devices and light-curing print materials. General components of UV-assisted 3D printing systems include beam projector, light beam, focusing system, prepolymer solution, and Z-axis motion platform. As shown in Fig. 8A, a prepolymer solution was irradiated by UV light directed by the focusing system. High-precision structures can be easily prepared by stereolithography or digital light processing (DLP) 3D printing. For example, a Y-shaped vascular scaffold encapsulated with fibroblasts was prepared by Wadnap et al. [102] using stereolithography. GelMA was chosen as the base material. After the determination of UV light intensity and exposure time, 3D cellular structures were successfully fabricated. Printing process parameters, especially exposure time, light intensity and concentrations significantly, affect the accuracy of scaffolds. Besides, diameters of patterns of digital mask affect the configuration of scaffolds. Wang et al. [103] fabricated a bilayer core-shell structure using DLP 3D printing. A cylindrical hydrogel structure was printed, and uncured hydrogel was washed away. Then a ring shape on around the cylindrical hydrogel was printed (Fig. 8B). This method requires stepby-step 3D printing. 


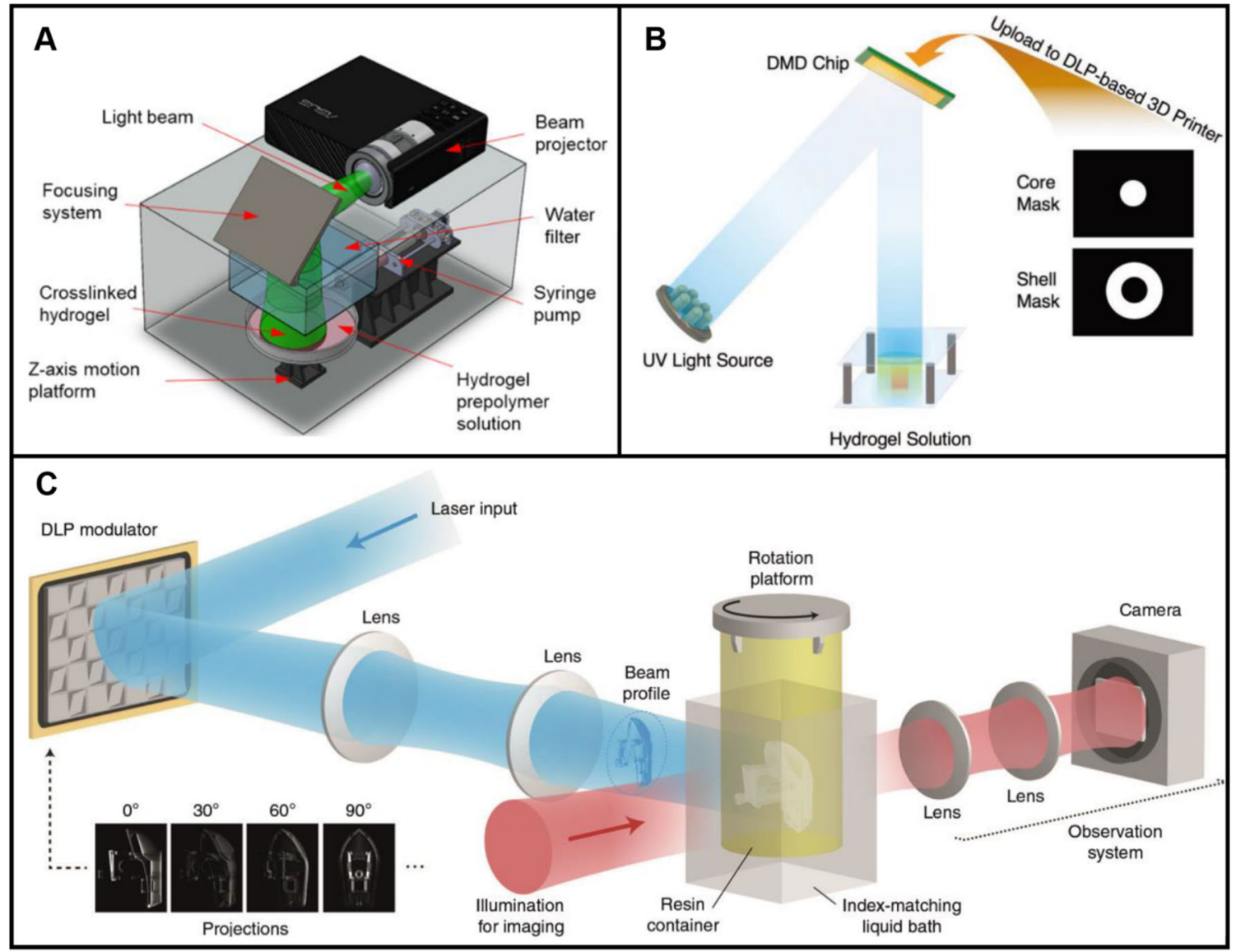

Fig. 8 UV-assisted 3D printing for scaffold-based vascular tissue engineering. A Preparation of GelMA scaffolds by stereolithography 3D printing. UV light was directed by a focusing system. Reproduced with permission [107]. Copyright 2018, American Chemical Society. B Preparation of bilayer core-shell structures by DLP printing. Based on a core and shell mask, a light pattern was formed. Reproduced with permission [103]. Copyright 2019, John Wiley and Sons. C Preparation of scaffolds by volumetric additive manufacturing via tomographic reconstruction. Reproduced with permission [105]. Copyright 2020, Loterie et al
To further improve the printing accuracy of scaffolds, Kim et al. [74] developed biocompatible silk fibroin materials for UV-assisted 3D printing. The print materials of good mechanical and rheological properties were prepared by a methacrylate process. Different from traditional 3D printing technology, Kelly et al. [104] proposed a new UV-assisted 3D printing method based on patterned UV irradiating from circumferential directions. One side of an inks-loaded container was irradiated by UV light. To achieve a patterned irradiation, the container was driven to rotate by a rotating shaft. In this method, all positions in 3D models can be cured simultaneously. Based on this method, an integrated feedback system was added by Loterie et al. [105] to precisely control the UV-curing process. The camera continuously recorded images during forming processes, which can be used as feedback for stopping irradiation of scaffolds (Fig. 8C). To validate the present approach, high-precision features were manufactured quickly. However, UV irradiating hinders cell differentiation and tissue formation. $\mathrm{UV}$-assisted $3 \mathrm{D}$ printing of biomaterial inks may be a temporary option for making vascular scaffolds. Recently, near-infrared (IR) light-assisted 3D printing has been reported, which overcomes the limitations of traditional UV-assisted 3D printing, including low light penetration, high photobleaching and damages to cells [106]. In view of these advantages, using this technology for fabricating vascular scaffolds is undoubtedly a research trend.

\section{Pros and cons: 3D printed vascular scaffolds}

Requirements for fabricating vascular scaffolds tend to be high-accuracy and manufacturable. And it is feasible to prepare complex vascular scaffolds by $3 \mathrm{D}$ printing following determination of appropriate print inks, component concentration, crosslinking methods and cells. Table 1 outlines studies of the preparation of vascular scaffolds utilizing 3D printing (extrusion-based, inkjet and UV-assisted 3D printing) technologies for formation of new blood vessel 
Table 1 Recent studies of the preparation of vascular scaffolds utilizing 3D printing (extrusion-based, inkjet, and UV-assisted 3D printing) technologies for formation of new blood vessel tissues

\begin{tabular}{|c|c|c|c|c|c|c|}
\hline 3D printing methods & $\begin{array}{l}\text { Biomaterial inks or } \\
\text { bioinks excluding } \\
\text { cells }\end{array}$ & $\begin{array}{l}\text { Component } \\
\text { concentration }\end{array}$ & $\begin{array}{l}\text { Physical or chemical } \\
\text { crosslinking }\end{array}$ & Cells & $\begin{array}{l}\text { Classification of } \\
\text { print materials }\end{array}$ & References \\
\hline Extrusion & $\begin{array}{l}\text { Bioinks excluding } \\
\text { cells (porcine } \\
\text { brain dECM) }\end{array}$ & $\begin{array}{l}1 \% \mathrm{w} / \mathrm{v} \text { porcine } \\
\text { brain } \mathrm{dECM}\end{array}$ & $\begin{array}{l}\text { Physical } \\
\text { crosslinking } \\
\text { (thermal } \\
\text { crosslinking) }\end{array}$ & $\begin{array}{l}\text { Human umbilical } \\
\text { vein endothelial } \\
\text { cells }+ \\
\text { glioblastoma cells }\end{array}$ & $\mathrm{dECM}$ & {$[108]$} \\
\hline Extrusion & $\begin{array}{l}\text { Biomaterial inks } \\
\text { (sodium alginate) }\end{array}$ & $\begin{array}{l}2 \% \mathrm{w} / \mathrm{v} \text { sodium } \\
\text { alginate }\end{array}$ & $\begin{array}{l}\text { Physical } \\
\text { crosslinking (ionic } \\
\left.\left(\mathrm{CaCl}_{2}\right)\right)\end{array}$ & N/A & Natural material & [109] \\
\hline Extrusion & $\begin{array}{l}\text { Bioinks excluding } \\
\text { cells (gelatin + } \\
\text { GelMA) }\end{array}$ & $\begin{array}{l}5 \% \text { w/v gelatin }+5 \% \\
\text { w/v GelMA }\end{array}$ & $\begin{array}{l}\text { Physical } \\
\text { crosslinking } \\
\text { (thermal } \\
\text { crosslinking } \\
\text { (gelatin, GelMA)) } \\
\text { and chemical } \\
\text { crosslinking (UV) }\end{array}$ & $\begin{array}{l}\text { Human umbilical } \\
\text { cord vein } \\
\text { endothelial cells }\end{array}$ & $\begin{array}{l}\text { Compositive } \\
\text { material }\end{array}$ & [110] \\
\hline Extrusion & $\begin{array}{l}\text { Bioinks excluding } \\
\text { cells (sodium } \\
\text { alginate) }\end{array}$ & $\begin{array}{l}5 \% \text { w/v sodium } \\
\text { alginate }\end{array}$ & $\begin{array}{l}\text { Physical } \\
\text { crosslinking (ionic } \\
\left(\mathrm{CaCl}_{2}\right) \text { ) }\end{array}$ & Mouse fibroblasts & Natural material & [111] \\
\hline Extrusion & $\begin{array}{l}\text { Biomaterial inks } \\
\text { (low-acyl gellan } \\
\text { gum + high-acyl } \\
\text { gellan gum) }\end{array}$ & $\begin{array}{l}3.4 \% \text { w/v low-acyl } \\
\text { gellan gum }+0.6 \% \\
\text { w/v high-acyl } \\
\text { gellan gum }\end{array}$ & $\begin{array}{l}\text { Physical } \\
\text { crosslinking } \\
\text { (thermal } \\
\text { crosslinking) }\end{array}$ & N/A & $\begin{array}{l}\text { Compositive } \\
\text { material }\end{array}$ & [112] \\
\hline Extrusion & $\begin{array}{l}\text { Biomaterial inks } \\
\text { (alginate }+ \\
\text { carboxymethyl } \\
\text { cellulose + } \\
\text { cellulose } \\
\text { nanofibers) }\end{array}$ & $\begin{array}{l}3 \% \text { wt. alginate }+ \\
3 \% \text { wt. } \\
\text { carboxymethyl } \\
\text { cellulose }+1.5 \% \\
\text { wt. cellulose } \\
\text { nanofibers }\end{array}$ & $\begin{array}{l}\text { Physical } \\
\text { crosslinking (ionic } \\
\left(\mathrm{CaCl}_{2}\right) \text { ) }\end{array}$ & N/A & $\begin{array}{l}\text { Compositive } \\
\text { material }\end{array}$ & [113] \\
\hline Extrusion & $\begin{array}{l}\text { Biomaterial inks } \\
\text { (nanoclay + } \\
\text { GelMA + } \\
\text { N-acryloyl } \\
\text { glycinamide) }\end{array}$ & $\begin{array}{l}10 \% \text { w/v nanoclay + } \\
1 \% / 9 \%(\mathrm{w} / \mathrm{v}) \\
\text { GelMA/N- } \\
\text { acryloyl } \\
\text { glycinamide }\end{array}$ & $\begin{array}{l}\text { Chemical } \\
\text { crosslinking (UV) }\end{array}$ & N/A & $\begin{array}{l}\text { Compositive } \\
\text { material }\end{array}$ & [114] \\
\hline Extrusion & $\begin{array}{l}\text { Bioinks excluding } \\
\text { cells } \\
\text { (semi-crosslinked } \\
\text { alginate/CaCl }{ }_{2}+ \\
\text { platelet-rich } \\
\text { plasma) }\end{array}$ & $\begin{array}{l}1 \% / 0.025 \%(\mathrm{w} / \mathrm{v}) \\
\text { semi-crosslinked } \\
\text { alginate/CaCl } \mathrm{CaCl}_{2}+ \\
50 \mathrm{UL} \mathrm{mL}^{-1} \\
\text { platelet-rich } \\
\text { plasma }\end{array}$ & $\begin{array}{l}\text { Physical } \\
\text { crosslinking (ionic } \\
\left(\mathrm{CaCl}_{2}\right) \text { ) }\end{array}$ & $\begin{array}{l}\text { Human umbilical } \\
\text { vein endothelial } \\
\text { cells }\end{array}$ & $\begin{array}{l}\text { dECM-based } \\
\text { compositive } \\
\text { material }\end{array}$ & [115] \\
\hline Inkjet & $\begin{array}{l}\text { Bioinks excluding } \\
\text { cells (sodium } \\
\text { alginate) }\end{array}$ & $\begin{array}{l}1 \% \mathrm{w} / \mathrm{v} \text { sodium } \\
\text { alginate }\end{array}$ & $\begin{array}{l}\text { Physical } \\
\text { crosslinking (ionic } \\
\left(\mathrm{CaCl}_{2}\right) \text { ) }\end{array}$ & $\begin{array}{l}\text { NIH } 3 \text { T3 mouse } \\
\text { fibroblasts }\end{array}$ & Natural material & {$[116,117]$} \\
\hline Inkjet & $\begin{array}{l}\text { Biomaterial inks } \\
\text { (sodium alginate) }\end{array}$ & $\begin{array}{l}0.8 \% \mathrm{w} / \mathrm{v} \text { sodium } \\
\text { alginate }\end{array}$ & $\begin{array}{l}\text { Physical } \\
\text { crosslinking (ionic } \\
\left(\mathrm{CaCl}_{2}\right) \text { ) }\end{array}$ & N/A & Natural material & [118-120] \\
\hline Inkjet & $\begin{array}{l}\text { Biomaterial inks } \\
\text { (bacterial cellulose } \\
+ \\
\text { polycaprolactone) }\end{array}$ & $\begin{array}{l}\text { bacterial cellulose } \\
\text { blended with } 10 \\
\text { wt. } \% \\
\text { polycaprolactone } \\
\text { at 5:95 ratio }\end{array}$ & $\begin{array}{l}\text { Physical } \\
\text { crosslinking } \\
\text { (thermal } \\
\text { crosslinking) }\end{array}$ & N/A & $\begin{array}{c}\text { Compositive } \\
\text { material }\end{array}$ & [121] \\
\hline Inkjet & $\begin{array}{l}\text { Bioinks excluding } \\
\text { cells (thrombin }+ \\
\mathrm{CaCl}_{2} \text { ) }\end{array}$ & $\begin{array}{l}50 \mathrm{unit} / \mathrm{ml} \text { thrombin } \\
+80 \mathrm{mM} \mathrm{CaCl}_{2}\end{array}$ & $\begin{array}{l}\text { Physical } \\
\text { crosslinking (ionic } \\
\left(\mathrm{CaCl}_{2}\right) \text { ) }\end{array}$ & $\begin{array}{l}\text { Human } \\
\text { microvascular } \\
\text { endothelial cells }\end{array}$ & $\begin{array}{c}\text { Compositive } \\
\text { material }\end{array}$ & [122] \\
\hline Inkjet & $\begin{array}{l}\text { Biomaterial inks } \\
\text { (polycaprolactone } \\
\text { + poly (acrylic } \\
\text { acid)) }\end{array}$ & $\begin{array}{l}70 \% \mathrm{w} / \mathrm{v} \\
\text { polycaprolactone } \\
+2.5,5 \text { and } 7.5 \% \\
\text { w/v poly (acrylic } \\
\text { acid) }\end{array}$ & $\begin{array}{l}\text { Physical } \\
\text { crosslinking } \\
\text { (thermal } \\
\text { crosslinking) }\end{array}$ & N/A & $\begin{array}{l}\text { Compositive } \\
\text { material }\end{array}$ & [123] \\
\hline Inkjet & $\begin{array}{l}\text { Biomaterial inks } \\
\text { (poly } \\
\text { (e-caprolactone)) }\end{array}$ & $\begin{array}{l}26 \mathrm{wt} . \% \text { poly } \\
\text { (e-caprolactone) }\end{array}$ & $\begin{array}{l}\text { Physical } \\
\text { crosslinking } \\
\text { (thermal } \\
\text { crosslinking) }\end{array}$ & N/A & Synthetic material & [124] \\
\hline
\end{tabular}


Table 1 continued

\begin{tabular}{|c|c|c|c|c|c|c|}
\hline 3D printing methods & $\begin{array}{l}\text { Biomaterial inks or } \\
\text { bioinks excluding } \\
\text { cells }\end{array}$ & $\begin{array}{l}\text { Component } \\
\text { concentration }\end{array}$ & $\begin{array}{l}\text { Physical or chemical } \\
\text { crosslinking }\end{array}$ & Cells & $\begin{array}{l}\text { Classification of } \\
\text { print materials }\end{array}$ & References \\
\hline $\begin{array}{l}\text { Inkjet-based 3D } \\
\text { printing }\end{array}$ & $\begin{array}{l}\text { Biomaterial inks } \\
\text { (polycaprolactone) }\end{array}$ & $\begin{array}{l}\text { Polycaprolactone } \\
\text { particle with the } \\
\text { molecular weight } \\
\text { of } 130,000 \mathrm{~g} / \mathrm{mol}\end{array}$ & $\begin{array}{l}\text { Physical } \\
\text { crosslinking } \\
\text { (thermal } \\
\text { crosslinking) }\end{array}$ & N/A & Synthetic material & {$[70]$} \\
\hline $\begin{array}{l}\text { Stereolithography } \\
\text { (SLA) }\end{array}$ & $\begin{array}{l}\text { Bioinks excluding } \\
\text { cells (GelMA) }\end{array}$ & $5 \%$ w/v GelMA & $\begin{array}{l}\text { Chemical } \\
\text { crosslinking (UV) }\end{array}$ & $\begin{array}{l}\text { Mouse 3T3 } \\
\text { fibroblasts }\end{array}$ & Synthetic material & {$[125]$} \\
\hline $\begin{array}{l}\text { Stereolithography } \\
\text { (SLA) }\end{array}$ & $\begin{array}{l}\text { Bioinks excluding } \\
\text { cells (GelMA) }\end{array}$ & $15,20 \%$ w/v GelMA & $\begin{array}{l}\text { Chemical } \\
\text { crosslinking (UV) }\end{array}$ & $\begin{array}{l}\text { NIH-3T3 fibroblast } \\
\text { cells }\end{array}$ & Synthetic material & {$[107]$} \\
\hline $\begin{array}{l}\text { Stereolithography } \\
\text { (DLP) }\end{array}$ & $\begin{array}{l}\text { Biomaterial inks } \\
\text { (poly(ethylene } \\
\text { glycol) diacrylate) }\end{array}$ & $\begin{array}{l}20 \% \text { w/v } \\
\text { poly(ethylene } \\
\text { glycol) diacrylate }\end{array}$ & $\begin{array}{l}\text { Chemical } \\
\text { crosslinking (UV) }\end{array}$ & N/A & Synthetic material & [126-128] \\
\hline $\begin{array}{l}\text { Stereolithography } \\
\text { (DLP) }\end{array}$ & $\begin{array}{l}\text { Biomaterial inks } \\
\text { (amino resin }+ \\
\text { dopamine }+ \\
\text { ammonium } \\
\text { persulfate) }\end{array}$ & $\begin{array}{l}50 \% \mathrm{w} / \mathrm{v} \text { amino } \\
\text { resin }+0.01-0.3 \% \\
\mathrm{w} / \mathrm{v} \text { dopamine }+ \\
0.12 \% \mathrm{w} / \mathrm{v} \\
\text { ammonium } \\
\text { persulfate }\end{array}$ & $\begin{array}{l}\text { Chemical } \\
\text { crosslinking (UV) }\end{array}$ & N/A & $\begin{array}{l}\text { Compositive } \\
\text { material }\end{array}$ & [129] \\
\hline $\begin{array}{l}\text { Stereolithography } \\
\text { (DLP) }\end{array}$ & $\begin{array}{l}\text { Bioinks excluding } \\
\text { cells (dECM + } \\
\text { GelMA) }\end{array}$ & $\begin{array}{l}5 \% \text { w/v dECM }+5 \% \\
\text { w/v GelMA }\end{array}$ & $\begin{array}{l}\text { Chemical } \\
\text { crosslinking (UV) }\end{array}$ & N/A & $\begin{array}{l}\text { dECM-based } \\
\text { compositive } \\
\text { material }\end{array}$ & {$[130]$} \\
\hline $\begin{array}{l}\text { Stereolithography } \\
\text { (DLP) }\end{array}$ & $\begin{array}{l}\text { Biomaterial inks } \\
\text { (poly(ethylene } \\
\text { glycol)- } \\
\text { tetraacrylate + silk } \\
\text { fibroin + melanin) }\end{array}$ & $\begin{array}{l}4 \text { wt. } \% \\
\text { poly(ethylene } \\
\text { glycol)- } \\
\text { tetraacrylate }+1 \\
\text { wt. } \% \text { silk fibroin }+ \\
0.2 \text { wt. } \% \text { melanin }\end{array}$ & $\begin{array}{l}\text { Chemical } \\
\text { crosslinking (UV) }\end{array}$ & N/A & $\begin{array}{l}\text { Compositive } \\
\text { material }\end{array}$ & [131] \\
\hline $\begin{array}{l}\text { Stereolithography } \\
\text { (DLP) }\end{array}$ & $\begin{array}{l}\text { Bioinks excluding } \\
\text { cells (glycidal } \\
\text { methacrylate- } \\
\text { hyaluronic acid + } \\
\text { GelMA) }\end{array}$ & $\begin{array}{l}1 \% \text { w/v glycidal } \\
\text { methacrylate- } \\
\text { hyaluronic acid }+ \\
2.5,5 \% \text { w/v } \\
\text { GelMA }\end{array}$ & $\begin{array}{l}\text { Chemical } \\
\text { crosslinking (UV) }\end{array}$ & $\begin{array}{l}\text { Human umbilical } \\
\text { vein endothelial } \\
\text { cells }+ \\
\text { C3H/10T1/2 cells }\end{array}$ & $\begin{array}{l}\text { Compositive } \\
\text { material }\end{array}$ & [132] \\
\hline $\begin{array}{l}\text { Stereolithography } \\
\text { (DLP) }\end{array}$ & $\begin{array}{l}\text { Biomaterial inks } \\
\text { (methacrylated } \\
\text { poly }(1,12 \\
\text { dodecamethylene } \\
\text { citrate)) }\end{array}$ & $\begin{array}{l}\text { 50-70\% wt./wt. } \\
\text { methacrylated } \\
\text { poly }(1,12 \\
\text { dodecamethylene } \\
\text { citrate) }\end{array}$ & $\begin{array}{l}\text { Chemical } \\
\text { crosslinking (UV) }\end{array}$ & N/A & Synthetic material & [133] \\
\hline $\begin{array}{l}\text { Volumetric } \\
\text { (SLA-based) }\end{array}$ & $\begin{array}{l}\text { Biomaterial inks } \\
\text { (GelMA) }\end{array}$ & $10 \%$ w/v GelMA & $\begin{array}{l}\text { Chemical } \\
\text { crosslinking (UV) }\end{array}$ & N/A & Synthetic material & [134] \\
\hline
\end{tabular}

tissues. Similar studies are discussed in the previous sections. Specially, gradient changes in material composition can be achieved by extrusion-based and inkjet 3D printing through variable mixing ratios of multiple components. As discussed, blood vessels are hierarchical structures. The interaction between different structures affects the functionalization of blood vessels. The gradient between different interfaces provides a way to ensure the strength of scaffold structures and the fusion between the vascular layers and the formation of vascularization. Besides, UV-assisted 3D printing contributes superior accuracy of vascular scaffolds. Based on principles of the above 3D printing methods, new $3 \mathrm{D}$ printing equipment integrating the strong points of different technologies is built to prepare customized scaffolds. This is also an effective means to overcome the contradiction between the high requirements for vascular scaffolds and the defects of different 3D printing technologies.

Printing accuracy, speed and cost are the three factors considered for preparing scaffolds by $3 \mathrm{D}$ printing. The cost for preparation of vascular scaffolds mainly includes the cost of 3D printing-based processes excluding print materials. Among extrusion-based, inkjet and UV-assisted 3D printing, extrusion-based 3D printers are low-cost but lowresolution. UV-assisted 3D printers are expensive. Inkjet 3D printers have low printing accuracy at high-frequency jets. 3D printing strategies of vascular scaffolds should be the preparation of anatomically matched scaffolds at low cost. In general, the fabrication of high-precision vascular scaffolds by extrusion-based 3D printing requires crosslinking characteristics of print materials because extrusion-based processes are relatively simple and economical. Interesting $3 \mathrm{D}$ printing methods such as $3 \mathrm{D}$ printing in suspension baths [26] and coaxial 3D printing have been derived. In traditional inkjet 3D printing, inks of low viscosity are required. There are not many reports for preparations of vascular scaffolds by traditional inkjet 3D printing [84]. Up to now, the effect of electric field forces on cell behavior remains to be studied. Thus, EHD 3D printing focuses on preparation of 
cell-free scaffolds. And UV-assisted 3D printing is limited by crosslinkable print materials and low light penetration. Both computational axial lithography and near-infrared photopolymerization significantly improve the preparation rate of vascular scaffolds [104, 135]. But there are fewer reports on these methods. Related researches on materials and printing devices need to be further investigated. The ultimate goal of print materials is to be commercialized and costeffective. Except for extrusion-based 3D printers and inkjet 3D printers, UV-assisted 3D printers are uneasily affordable for researchers in developing countries. The code of control program needs to be open access to set up 3D printers for preparing individualized vascular scaffolds. More commercial devices and manufacturing methods are presumed to be combined and exploited to prepare vascular scaffolds. After that, low-cost and high-precision preparation of scaffolds will be realized.

\section{Commonly used integrated technologies}

\section{Integrated technology of casting and 3D printing}

Casting is a traditional manufacturing method. Preparation of complex structures by 3D printing are often involved to remove support materials. Mold forming contributes to removing these materials and mass produce. By combining 3D printing and traditional manufacturing technologies, various vascular scaffolds can be designed and prepared. Extrusion-based 3D printing requires rheological properties of print materials. For sacrificial materials, carbopol as a sacrificial gel to fabricate vascular scaffolds was introduced [48]. The sacrifice material possessed shear thinning properties and was extruded by an extrusion-based 3D printer to create personalized vascular structures. In this process, frames with another material were initially printed. Next, sacrifice structures were printed with carbopol and then casting materials were poured to overlay the printed carbopol. After the casting materials were cured and the sacrificial material was removed, scaffolds were prepared (Fig. 9A). As the traditional casting technology has been widely studied in mechanical discipline and molds are easy to be prepared using 3D printing, now it has become one of the main methods to prepare vascular scaffolds because of the research progress of sacrificial materials. Nie et al. [136] reported an integrated method, mold casting and inkjet 3D printing and fused deposition modeling (FDM) 3D printing, to fabricate vascular scaffolds. An inkjet 3D printer was used to print ultrafine fiber networks of vascular channels. Hydrogels were then casted into fiber networks to form hydrogel sheets. Hydrogels were cured at $4{ }^{\circ} \mathrm{C}$. After the removal of fiber materials, scaffolds with internal vascular networks were formed by hydrogel sheet bonding using UV curing (Fig. 9B). The printing accuracy of vascular scaffolds depends on the printing resolution of fibrous structures. Multi-scale vascular networks can be manufactured in this way. But the entire process is complex and requires twice-crosslinking, leading to damaged scaffolds after demolding. For demolding, Lv et al. [99] reported in-depth analysis of demolding methods. Separable molds were prepared by inkjet 3D printing, and hydrogels were casted and cured by UV curing. Compared to integral molds, separable molds reduced surface contact during demolding and achieved perfect demolding. Skylar-Scott et al. [137] prepared a heart model including a left anterior descending (LAD) artery and a diagonal branch, using integrated technology of UV-assisted 3D printing, casting, and embedded 3D printing, as shown in Fig. 9C. First, a mold for the heart model was fabricated by UV-assisted 3D printing. Then the model was filled with cardiac tissue matrixes by casting. Finally, the artery and diagonal branch were printed by embedded 3D printing, respectively. This process contributes to the successful preparation of such complex organs because the configuration of organs and the formation of a vascularized network are guaranteed.

Overall, casting techniques involving 3D printing can enable the preparation of complex molds and vascular scaffolds. There are individualized differences in vascular morphology of patients in clinical treatments and researches. For individualized scaffolds, the preparation process is quite simple, because 3D models can be easily obtained through parametric design or reverse engineering. However, regardless of what 3D printing processes, scaffold modeling is required. Mold preparation by corrosion casting may help solve the problem. The principle of corrosion casting is similar to reverse engineering. Corrosion casting can directly extract structures of vascular scaffolds. Compared with traditional structure modeling and preparation methods, structures obtained by corrosion casting are more bionic. The preparation of vascular scaffolds using corrosion casting was reported by Huling and workers [138], as shown in Fig. 9D. The process began with the perfusion of PCL solution and acetone into native kidney tissues for enough days until acetone evaporation. Then, vascular corrosion cast was achieved after the dissolution of tissues by sodium hydroxide. Next, the PCL cast was dip-coated with collagen. Vascular scaffolds were finally prepared by the crosslinking of collagen and dissolution of PCL cast. In this method, vascular corrosion cast obtained from solution perfused into blood vessels is regarded as the process of scanning points cloud data in reverse engineering. The process of obtaining a vascular scaffold is seen as the process of reconstructing and manufacturing 3D model based on points cloud data. Usual vascular scaffolds are designed and manufactured according to the shape of original blood vessels. But limited by printing accuracy of 3D printing and conventional manufacturing technologies, this conventional method can only achieve the preparation of simple structures, or the preparation of 


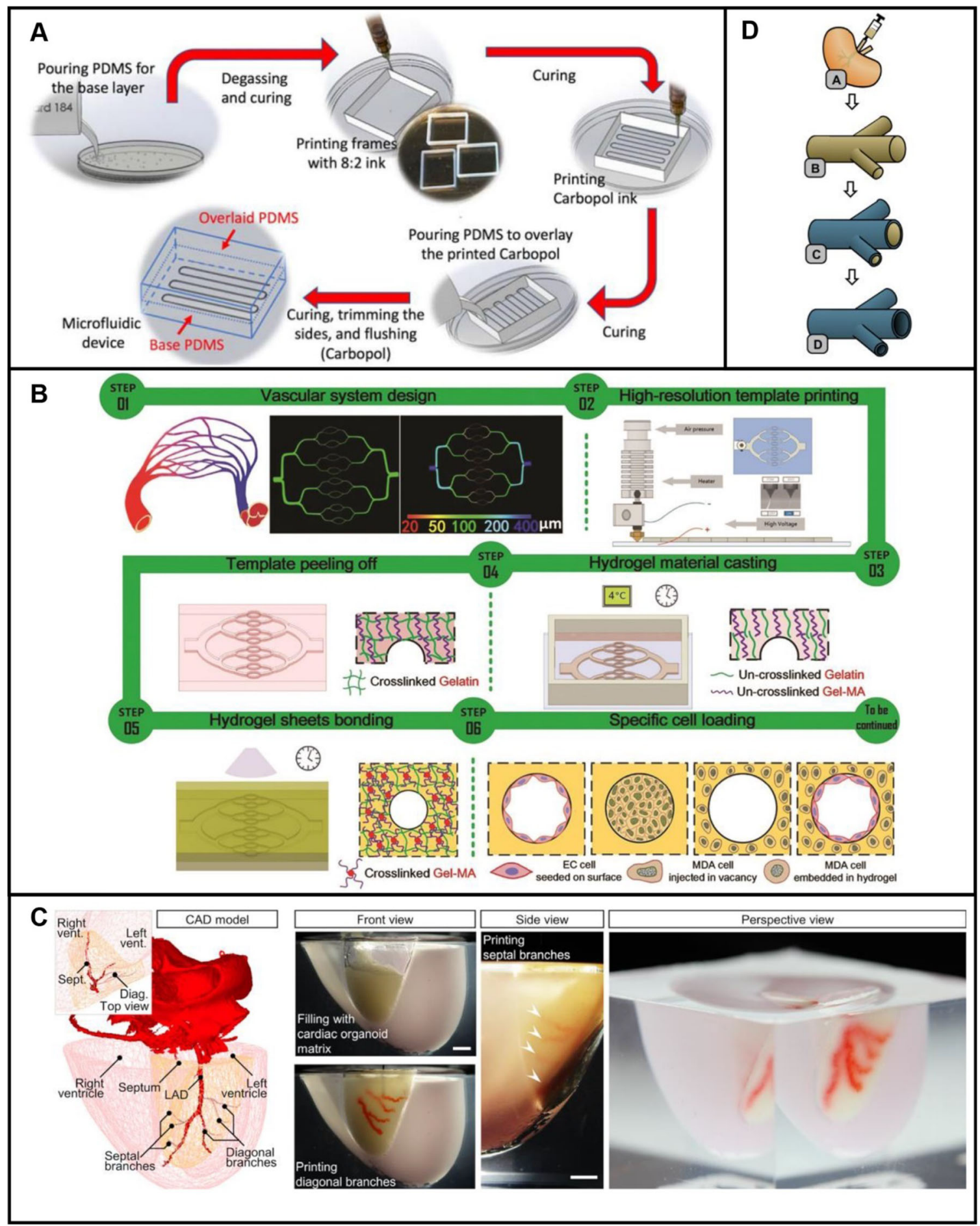

Fig. 9 Preparation processes of vascular scaffolds by the integrated technology of casting and 3D printing: A Preparation of vascular scaffolds by the integrated technology of casting and extrusion-based 3D printing. Reproduced with permission [48]. Copyright 2019, IOP Publishing. B Preparation of vascular scaffolds by the integrated technology of casting and EHD 3D printing and FDM 3D printing. Reproduced with permission [136]. Copyright 2020, The Royal Society of Chemistry.
C Preparation of cardiac tissues by the integrated technology of UVassisted 3D printing to prepare a cardiac mold, casting to fill with matrix, and embedded 3D printing to fabricate vascular networks. Reproduced with permission [137]. Copyright 2019, Skylar-Scott et al. D Preparation of vascular scaffolds by corrosion casting with solution perfused into blood vessels. Reproduced with permission [138]. Copyright 2016, Elsevier 
scaffolds but requires the extra introduction of additional processes such as bonding. Besides, increased processes may lead to inaccurate structural accuracy and pollution issues. Structures such as configuration or sacrificial models of scaffolds can be fabricated by corrosion casting, paving an avenue for preparation of bionic vascular scaffolds.

\section{Integrated technology of electrospinning and 3D printing}

Compared with 3D printing, electrospinning is also exploited to prepare vascular scaffolds. This is due to its competitiveness in the fabrication of uniform fibers of small diameter, small pore size, and high porosity. The mechanism of electrospinning processes is to eject inks by a certain pressure and high-voltage electric field forces. When the electrostatic field force of microdroplets of inks is greater than the surface tension, the microdroplet is accelerated and sucked out by the electrostatic fields to form a fiber structure. Electrospinning devices are similar to devices of EHD 3D printing. But there are obvious differences between them. An inkjet 3D printing process is initially driven by piezoelectric, thermal bubbles or high-pressure ultrasonic waves. And an electrospinning process is initially driven by external pressures. Besides, the structures of a material created at the nozzles are also different. Electrospinning prepares fibers, while inkjet 3D printing forms droplets or small particles. According to the state of the materials during electrospinning, it is divided into solution electrospinning and melt electrospinning. The efficiency of solution electrospinning is low, and sometimes toxic solvents are introduced to satisfy the processes. These defects are avoided by melt electrospinning. To improve the accuracy of scaffolds prepared, printing speed and path planning and movement speed of collectors in electrospinning are investigated. Jin et al. [139] fabricated heterogeneous scaffolds by changeable relative motion between a collector and a spinneret of this forming process. The accumulation of different bioinks caused by printing speed was considered here. Similarly, Castilho et al. [140] investigated the effect of collector motion and velocity profiles to improve the accuracy of fiber deposition. But this method only optimizes preparations of square, rectangular, and hexagonal geometric models.

Integrated technology of electrospinning and 3D printing shows unique advantages in the field of preparation of tissue engineering vascular scaffolds because the parameters of small diameter, small pore size and high porosity, which can be achieved by electrospinning, are the significant features of the physiological structure of blood vessels. And as we discussed, 3D printing has shown outstanding strengths in this domain. Integrated technology of electrospinning and extrusion-based 3D printing is common, attributed to multiple devices and materials available in extrusion-based 3D printing. Gao et al. [49] fabricated assembled cell-laden structures (Fig. 10A). The macrostructure and microstruc- ture of a support were fabricated by extrusion-based 3D printing and electrospinning, respectively. Depositions of the bioink on the support were controlled by extrusion-based 3D printing technology. Also, extrusion-based 3D printing of biomaterial inks can be used as support materials for vascular cells [141]. Uniaxially micropatterned struts were fabricated by Yeo et al. [142] using extrusion-based 3D printing of the compositive material of PCL and collagen. Then the structs were covered by fibers prepared by electrospinning of a bioink including polyethylene oxide alginate and endothelial cells. And alignment and differentiation of the cells were induced. Integrated technology of electrospinning and inkjet 3D printing is also reported. Devices consist of a combination of separate devices or an integrated device with the hybrid technology. As shown in Fig. 10Bi, a combined method was used to fabricate vascular scaffolds [62]. Based on a rotating rod, the inner layer was printed by inkjet 3D printing, and subsequently the outer layer was printed by electrospinning. Experimental results show that the spiralflow of bloods and wall-shear stress of vascular cells were improved. Huang et al. [143] prepared triple-Layer vascular scaffolds by integrated technology of EHD 3D printing and electrospinning. First, an aligned inner layer was fabricated by electrospinning. Second, a corresponding compact middle layer was prepared by EHD 3D printing. Then, the exterior layer consisting of two types of fibers was fabricated by coelectrospining. This method avoids the inadequate porosity and lowly cell penetration of traditional vascular scaffolds. In view of the similarities between EHD 3D printing and electrospinning, an interesting integrated device was proposed by Wu et al. [144] Both electrospinning and EHD 3D printing were easily achieved by this device (Fig. 10Bii). Integrated technology of electrospinning and UV-assisted 3D printing is also investigated. Lee et al. [145] fabricated aligned microfibers by electrospinning of the compositive material of PCL and gelatin. Subsequently, a polyethylene (glycol) scaffold embedded with the microfibers was prepared by UV-assisted 3D printing (Fig. 10C). Vascular tissue formation was improved by using this scaffold. In addition to the methods discussed above, vascular scaffolds with complex hollow structures can also be prepared by $3 \mathrm{D}$ printing and electrospinning, through the removal of sacrificial materials fabricated by 3D printing [146]. Overall, nano-/microfiber patterns with porous structures are easily fabricated by combining electrospinning and 3D printing. The function of this integrated technology for preparation of vascular scaffolds is presumed to be achieved by separate devices or integrated devices. The integrated devices may be a direction due to their hopeful possibility of high-speed manufacturing, sterile environments, and mass production. This integrated technology is expected to be further reported in multi-step additive manufacturing or processes of combination of additive manufacturing and subtractive manufacturing. 


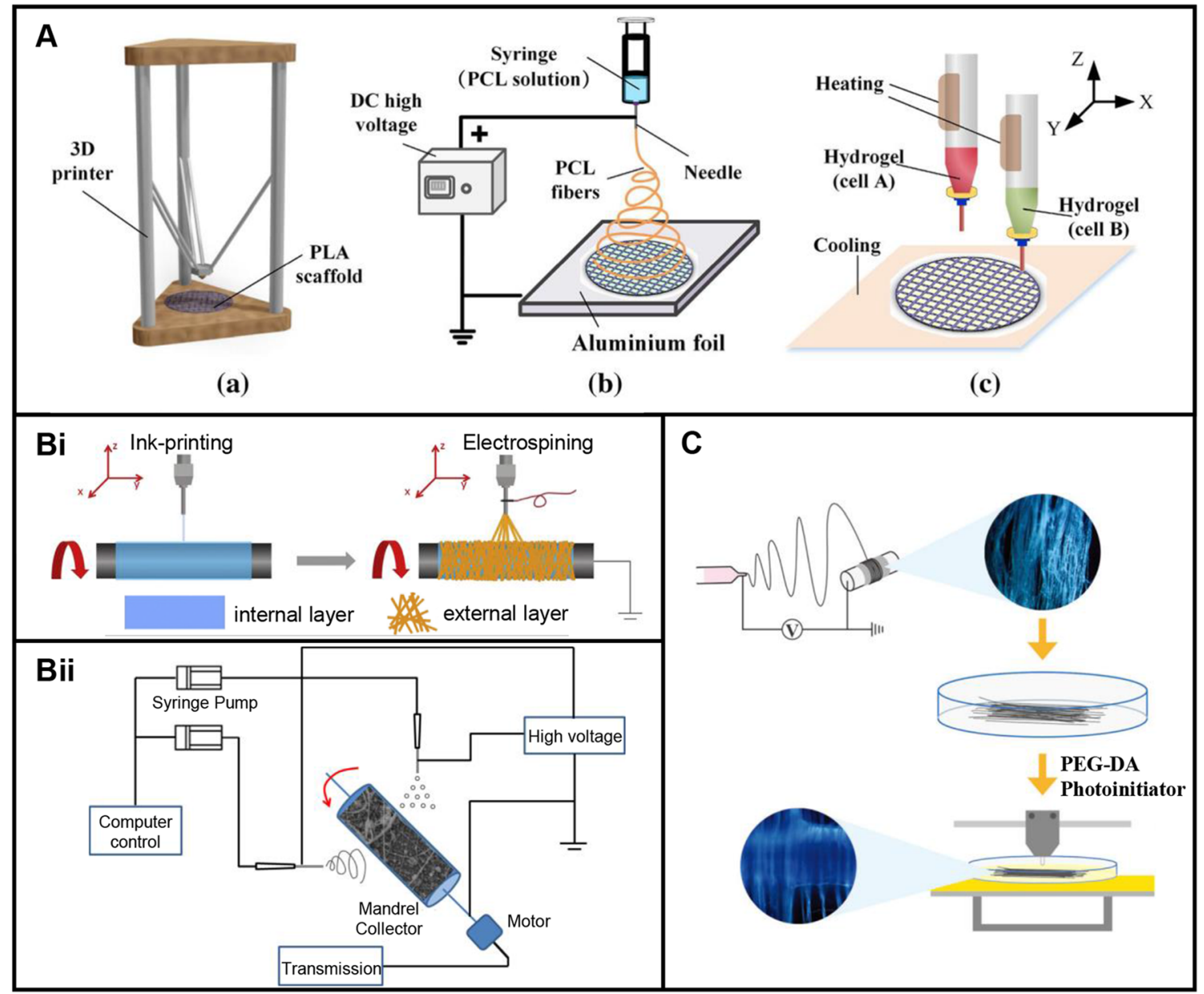

Fig. 10 Preparation of vascular scaffolds by the integrated technology of electrospinning and 3D printing: A Preparation of surface structures by the integrated technology of electrospinning and extrusion-based 3D printing to fabricate assembled cell-laden sheets. Reproduced with permission [49]. Copyright 2019, Springer Nature. B Integrated technology of electrospinning and inkjet 3D printing: Bi Preparation of vascular scaffolds by the integrated technology of electrospinning and inkjet 3D printing. Reproduced with permission [62]. Copyright 2018, Else-

\section{Integrated technology of Lego-like construction and 3D printing}

Figuratively speaking, Lego-like construction is a Lego-like modular method of building blocks. Lego-like construction is based on separated scaffold modules to assemble into complex vascular scaffolds. With the increasing demand, a single vascular scaffold may no longer meet the requirements. Multiple functional modules such as flow channel, cell culture, and regulations can be provided by multi-module scaffolds. Each module can be prepared by traditional manufacturing and 3D printing technology. Based on the method of Legolike construction, detachable integral vascular scaffolds can be fabricated. Since the materials involved in the integrated vier. Bii Preparation of vascular scaffolds by the integrated technology of electrospinning and EHD 3D printing based on a hybrid electrospinning and EHD 3D printing system. Reproduced with permission [144]. Copyright 2017, Emerald Publishing Limited. C Preparation of vascular scaffolds by the integrated technology of electrospinning and stereolithography. Reproduced with permission [145]. Copyright 2017, Mary Ann Liebert, Inc

technology are almost the same as in 3D printing, only 3D structures and assembly of the basic modules are discussed in focus. Speaking of the fabrication of this type of vascular scaffolds, how to realize the assembly between modules? Generally, connectors, especially cylindrical connectors, are involved. There are two types of connectors: separate components [147] or components integrated into the main modules [148]. Common processes for preparing connectors include $3 \mathrm{D}$ printing or the combination of 3D printing and casting. Subbiah et al. [149] designed a miniaturized hollow microcage as the basic module for assembly. A miniature basic module with a volume of $3.375 \mathrm{~mm}^{3}$, a hollow size of $1.5 \times 1.5 \times 1.5 \mathrm{~mm}$ and a wall thickness of $230-560 \mu \mathrm{m}$, was constructed by DLP 3D printing. A scaffold was fabri- 
cated based on the assembly between the same basic modules. These pore structures in the basic module promote cell invasion and vascularization.

The integrated scaffolds are not only assembled by a same module, but also different modules. Customized vascular scaffolds are created through a diverse combination of different modules. As shown in Fig. 11A, a rapidly reconfigurable modular device was used as a convenient way to fabricate vascular scaffolds [50]. First, scaffold modules with different microchannels were prepared by 3D printing technology. Then surfaces of these scaffold modules were treated with PDMS at $60{ }^{\circ} \mathrm{C}$ for about an hour. Different forms of structures were assembled by using multiple modules. After the microchannels were filled with a capillary material, an integral vascular scaffold was prepared. Similar to the above work, Valentin et al. [150] prepared modules by stereolithography, and then the modules were assembled into a scaffold. The difference was the connector integrated into the basic modules in this research.

Casting technology as an auxiliary process was also involved. A conventional method was reported by Qiu's team [151] to fabricate organ-on-a-chip (Fig. 11B). The difference between the two methods was that Qiu adopted an integrated technology of 3D printing and conventional casting to achieve the fabrication of scaffolds with microchannel structures. In this way, although the preparation of the mold involved a curing process, more complex modular structures can be obtained. But simulation of vascular microenvironments is improper by this simple strategy. Microchannels with electro-transfection function were fabricated by Zhu et al. to simulate the microenvironments [152]. First, a mold for basic models was prepared by stereolithography. Second, metal particles were sprayed on the mold. After pouring PDMS, the basic PDMS modules were obtained by demolding. And then the scaffold was fabricated by assembly. In some cases, scaffolds with functions of real-time observation and regulation need to be created. The integrated technology plays an important role in the creation of scaffolds with functional modules. Optical modules were involved by Lee et al. [153] using stereography. A scaffold was fabricated by the assembly between the optical blocks and the fluid blocks. The method of monitoring cell growth and tissue formation was achieved.

It is quite difficult to directly prepare vascular scaffolds matching multiple types of blood vessels. The assembly of a variety of blocks provides a solution to this problem [148]. In general, the prepared scaffold modules are flexible and detachable. Each module can be used as a component for vascular scaffolds with different functions. Surface of different modules can be easily coated or plasma-treated before tests. And residual reagents can be easily cleaned after experiments. Based on the integrated technology, it is envisaged that multiple types of blood vessels may be prepared. Even though Lego-like construction methods are simple and show versatile functions for vascular scaffolds, the assembly accuracy and sealing issues are still challenging problems. Thus, it is not suitable for culturing vascular cells with medium of high hydrostatic pressure, which limits its application in tissue engineering. To avoid leaks, surface quality of the interface between modules needs to be thoroughly investigated. Yet surface quality of scaffolds prepared by 3D printing is limited. Besides, as Lego-like construction of scaffolds is usually manual, the risk of introducing contamination is high. Due to the high requirement of assembling accuracy, a promising method is to integrate other technologies such as casting, micromilling, and grinding to achieve precise assembly [154]. Advances in robotics and automation control technology will also bring new hopes for the application of Lego-like construction to vascular scaffolds.

\section{Pros and cons: vascular scaffolds prepared by integrated technologies}

As shown in Table 2, there are three integrated technologies discussed above, including casting and 3D printing, electrospinning, and 3D printing, and Lego-like construction and 3D printing. It's hard to give an exact answer which integrated technology is better, because a certain technology is more suitable for some specific situation. Taking the integrated technology of casting and 3D printing as an example, it presents unparalleled advantages in the preparation of porous structures and mass production of vascular scaffolds. Mass production is conducive to the fabrications of off-the-shelf scaffolds and promotes their commercialization. And based on these strengths of casting technology, its application is expected to be involved in many integrated technologies. Compared to traditional casting, although corrosion cast provides a high anatomical match to original blood vessels, the process is complex. The solution is subject to fluid resistance during the perfusion process, especially where the vessel is bifurcated and the diameter is small. Discontinuous vascular scaffolds are easily formed. In contrast, integrated technology of electrospinning and 3D printing plays a key role in the preparation of vascular scaffolds with surface morphology with micro-/nanoscale features such as randomly oriented fibers. High-strength scaffolds or non-crossing patterns for regulating cell growth can be achieved by 3D printing. And an outer layer or inner layer of 3D printed structures can be prepared by electrospinning. But the integrated technology is not suitable for mass production. This is a stumbling block to the standardization and commercialization of vascular scaffolds. Compared with the two integrated technologies discussed, the integrated technology of Lego-like construction and 3D printing points out a solution for fabrication of vascular scaffolds from another perspective. Fabrication and assembly of basic blocks by this integrated technology pro- 


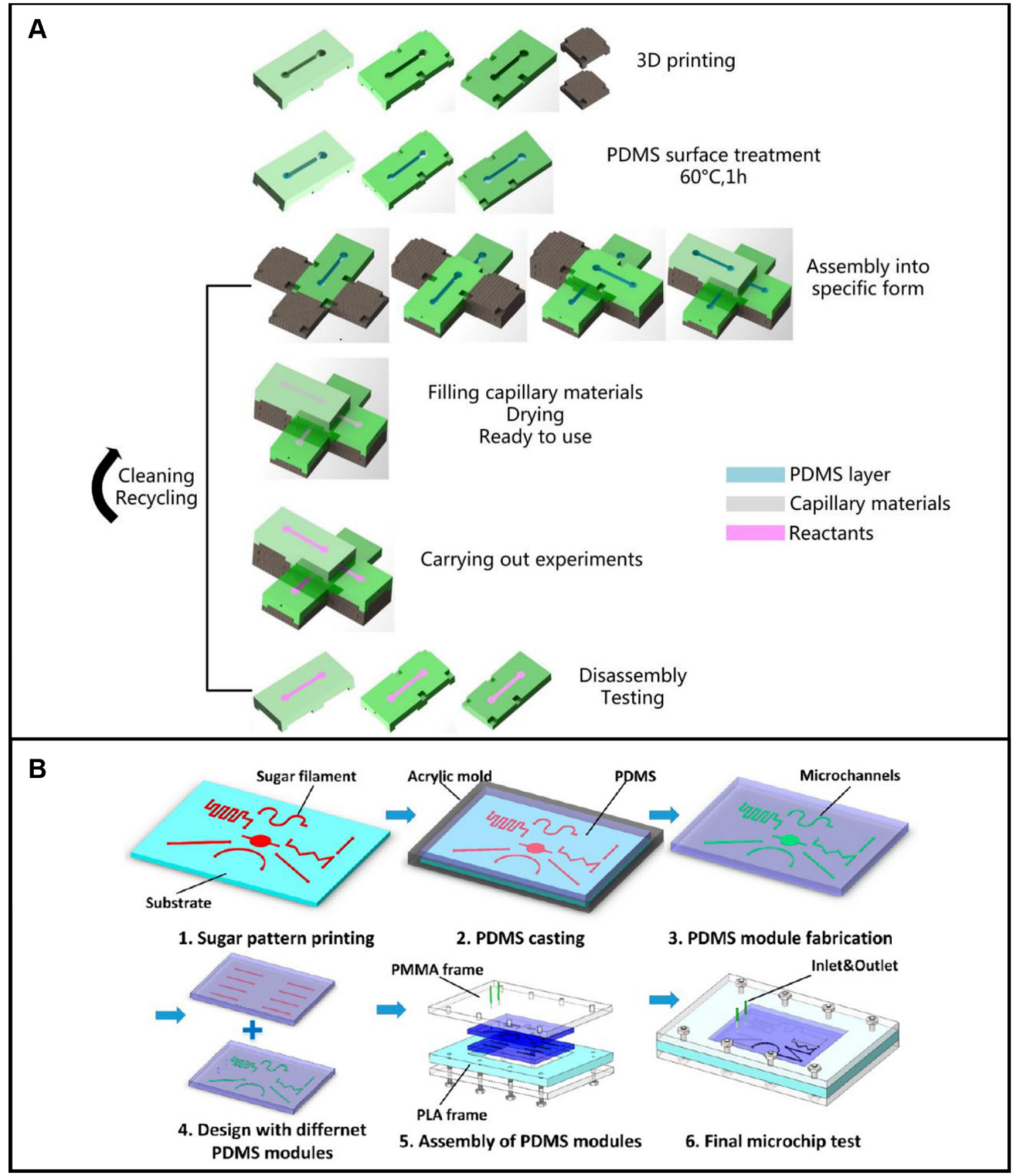

Fig. 11 Preparation of vascular scaffolds by the integrated technology of Lego-like construction and 3D printing: A Preparation of vascular scaffolds by the integrated technology of Lego-like construction and $3 \mathrm{D}$ printing to prepare detachable integral vascular scaffolds with multiple functional modules of flow channel, cell culture, and regulation.
Reproduced with permission [50] Copyright 2018, IOP Publishing. B Preparation of scaffolds by the integrated technology of Lego-like construction, 3D printing and conventional casting technology to prepare scaffolds with microchannel structures. Reproduced with permission [151]. Copyright 2017, American Chemical Society vide the possibility for the preparation of complex vascular scaffolds. But some shortcomings of this technology are outstanding in tissue engineering, such as the limited strength of scaffolds at the connections between blocks. In addition, for engineering blood vessels, smooth surfaces of scaffolds are required. So, the interaction interface between blocks is required to be smoothly transitioned, and bumps and pits are not allowed.

However, some tissue and function cannot be achieved by conventional manufacturing methods. Cell regulation is 


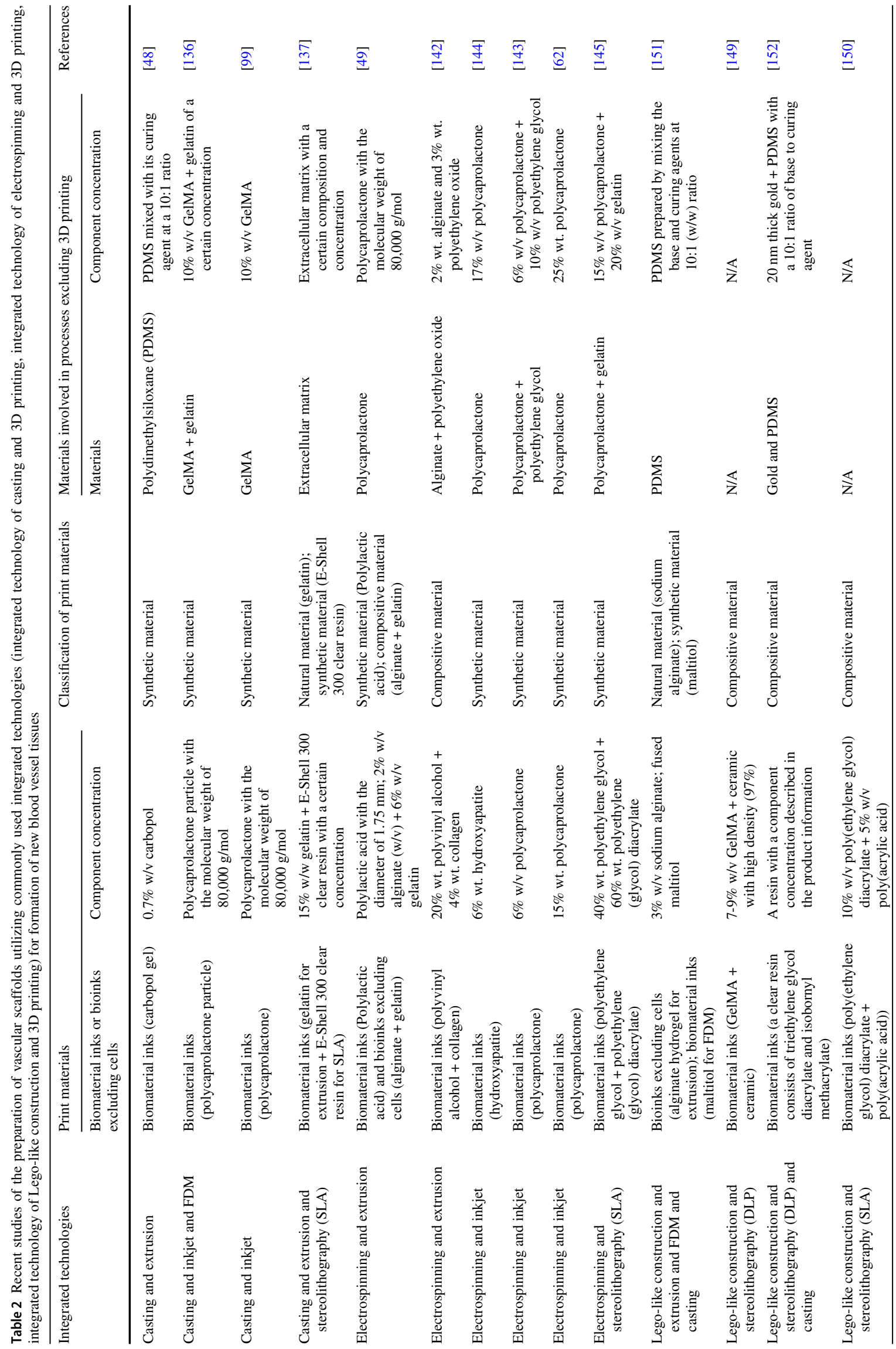


a promising method to overcome the problem. For example, to prepare tiny blood vessels, the design of vascular scaffolds considering cell regulation was reported by Kim et al. [55] First two microchannels were flanked by a central channel and separated by microposts. And two cell culture chambers were placed on the left and right outermost sides, which allowed different cell distributions. Next, after the chip was prepared, the central microfluidic channel and outermost culture chambers were coated with different inks to induce vasculogenesis and angiogenesis. That is, large blood vessels were guided to form by vascular scaffolds, and small blood vessels were directed to form by the regulation modules embedded in corresponding scaffolds. Unconventional methods like this need to be considered and valued.

After fabrication, it is necessary to ensure the feasibility of these scaffolds in single cultures versus co-co-culturebased techniques. The requirements of different $3 \mathrm{D}$ printed scaffolds for culture conditions are similar. Take these widely used extrusion-based 3D printed scaffolds as examples, there are some aspects that need to be characterized: (i) evaluate the error of the printed scaffolds comparing to the data models by imaging technology [155]; (ii) ensure accurate spatial distribution of cells on the scaffolds after extrusion-based 3D printing [54]; (iii) ensure the matching between the internal and surface structure of the scaffold and the type of cells to be seeded [156]; (iv) evaluate oxygen and nutrient content of scaffolds with channels by biological experiments [2]; (v) ensure cell survive after the printing and evaluate cytocompatibility of the scaffolds $[157,158]$. Subsequently, these 3D printed blood vessels are cultured in vitro in single cultures or co-culture. To enable long-term cultures, some approaches are listed: (i) add some components including corresponding cell growth factors, fibronectin, heparin, thrombin, and so on [159-161]; (ii) maintain suitable $\mathrm{pH}$ and improve the quality of serum in culture medium [51, 52]; (iii) exploit the paracrine of other cells such as osteoblasts and sarcomaderived cells $[162,163]$.

\section{Transformation of vascular scaffolds to clinical productivity}

\section{Estimation of scaffold properties by different integrated technologies}

Vascular scaffolds not only serve as carriers for cells, but also support the formation of blood vessel tissues. Different vascular tissues match the corresponding prepared scaffolds. The properties of vascular scaffolds include the connectivity, 3D configuration, biophysical properties, and biochemical properties [36], as shown in Fig. 12. These properties are usually evaluated through experiments. May the redundant evolutions be simplified? Seemingly estimation of the properties of scaffolds prepared by different 3D printingbased integrated technologies is an interesting and necessary approach. The estimation may benefit transformation of artificial vessels to clinical productivity.

Spatial and temporal resolution for cell growth and tissue formation are provided by 3D configurations of vascular scaffolds. There is a difference in configuration between scaffold models and the prepared scaffolds, such as the size of aperture and the wall thickness [25]. To estimate configuration of the prepared scaffolds, process errors should be considered in procedures such as extrusion-based 3D printing of corners of models, path planning in EHD 3D printing, UV-assisted 3D printing of supports for easily deformable structures. In electrospinning, fiber diameters can be predicted by the process parameters. And high demolding accuracy of casting and assembly accuracy of Lego-like construction reduce the geometric error of the configurations, laying the foundation for the precise estimates. Moreover, biomaterials such as hydrogels are commonly used in 3D printing. The swelling characteristic [164] of these materials is also an indispensable factor that needs to be considered when evaluating scaffold configurations.

Besides, estimation of connectivity of scaffolds is also necessary. The connectivity of scaffolds is conducive to cell-cell interactions [8]. Although the connectivity is presented by models of vascular scaffolds, both processes of the preparation by integrated technologies and the auxiliary processes affect the connectivity. There are two common aspects needed to be considered when estimating connectivity of these scaffolds. One is to ensure sacrificial material removal. Although sacrificial materials or composite materials involving sacrificial materials can be prepared by 3D printing and removed by methods such as dissolution [23], incomplete removal of sacrificial material is commonly formed in complex structures. The other is to avoid collapse because of insufficient strength of scaffolds. For instance, fibers or Lego-like blocks are sometimes involved in fabrication of scaffolds. Fibers prepared by electrospinning and Lego-like blocks fabricated by assembly may easily deform and collapse following the exertion of external forces.

Estimation of biophysical properties of scaffolds is essential. Vascular cells are subjected to hydrodynamic and static pressures of blood [36]. Hydrodynamic pressures include shear, hydrostatic pressure, and cyclic stress [165]. Requirements of vascular scaffolds to match the biophysical microenvironments of vascular cells mainly include three points: certain surface topologies, mechanical strength and stiffness. Topological structures of a scaffold surface can be controlled by technologies such as 3D printing technology, integrated technology of casting and 3D printing, integrated technology of electrospinning and 3D printing. And there exists similarity in estimation methods between topologies and the configurations of scaffolds mentioned previously. In 
Fig. 12 Estimation of vascular scaffold properties by different integrated technologies and their effects on vascular cell growth and tissue vascularization

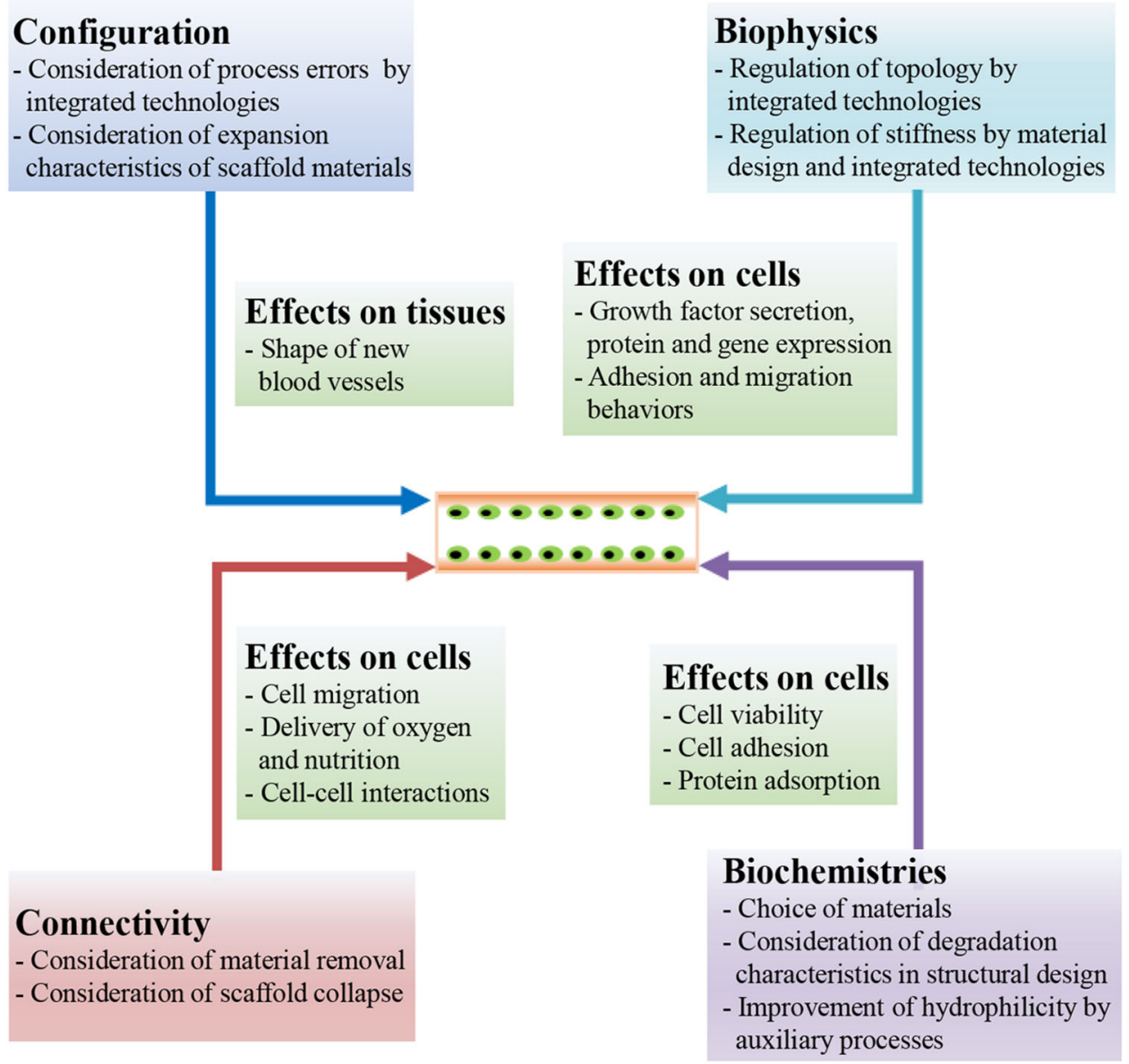

addition, simulation software is useful tools to estimate the strength and bearing capacity of scaffolds under biomechanical conditions of cells (e.g. shear force, hydrostatic pressure, cyclic stress). Also, both strength and stiffness of scaffolds can be speculated by proper concentration of material composition, UV irradiation and crosslinking time of inkjet 3D printing and UV-assisted 3D printing.

Biochemical properties of scaffolds also regulate the vascularization of cells. Cell-friendly, implantable, and degradable properties of vascular scaffolds are the prerequisites for implantation [19-21]. Biochemical properties are determined by materials used in integrated technologies. Some of these properties need to be estimated, such as biocompatibility, degradation characteristics, and hydrophilicity. Estimation of biocompatibility can be based on guidelines provided by regulatory authorities. Moreover, the spatial and temporal scaffold structures are controlled by degradation properties of scaffolds [13]. A general method [19] to estimate its degradation rates in vivo is to evaluate the properties in vitro based on simulation of cell microenvironments. Besides, the hydrophilicity and hydrophobicity of scaffolds are determined by the surface materials. Hydrophilic surfaces are not conducive to protein adsorption, leading to poor cell adhesion and tissue vascularization. In some cases, original materials of vascular scaffolds are not hydrophilic. Scaffolds may need to be coated with auxiliary hydrophilic materials by $3 \mathrm{D}$ printing, casting, or electrospinning technology.

\section{Clinical translation of vascular scaffolds}

Tissue engineering provides effective ways for tissue regeneration and organ replacement. Among the causes of human death in patients, vascular diseases are widely involved. Specially, Varga et al. [166] found that the global public health disease COVID-19 was not only a respiratory disease, but also a widespread vascular disease. This importance and urgency require transformation of artificial vessels to clinical productivity. A common method for fabrication of vascular grafts is scaffold-based tissue engineering. After preparation of scaffolds by different integrated technologies, it is essential to be applied to animal experiments and clinical cases. There are two stages of scaffold-based tissue engineering before clinical application. One is to verify the properties of scaffolds to match specific clinical cases. The other is the culture of scaffolds with cell seeding or loading. 
Verification of scaffold properties includes configuration, connectivity, and biophysical and biochemical properties. Methods of micro-CT scan and MRI are usually used to evaluate configurations of the structures [79]. As we known, to achieve the adhesion and distribution of vascular cells on scaffolds, perfusion of cells into microchannels is a common means. Inspired by this strategy, evaluation of connectivity can be performed by perfusion [22]. The microfluidic channels are filled with cell culture media or color dyes to test the connectivity of scaffolds for tissue vascularization. And the study of vascular mechanical properties is performed by static and hydrodynamic loading to evaluate the mechanical properties of vascular scaffolds to maintain structural stability in vivo [165]. Biocompatibility of vascular scaffolds can be evaluated in vitro and in vivo via various qualitative or quantitative methods, such as 4succinate dehydrogenase activity (MTT assay), fluorescent stainings (e.g. live/dead staining), flow cytometry (FCM), and so on [167-170]. And the specificity of artificial vessels can be evaluated by conducting fluorescent stainings, ELISA or PCR [171-173]. Specially, the involved live/dead staining and fluorescent staining can be visualized under a light/electron or a multiphoton microscope. And the CD31 and VEGF level of blood vessels can be quantified by ELISA and particular gene expression can be confirmed by PCR. Furthermore, the inflammatory factors (e.g. tumor necrosis factor- $\alpha$ (TNF- $\alpha$ ), interleukins $1 \beta$ and 6 (IL-1 $\beta$ and IL6)) after implanting vascular scaffolds can be measured by ELISA [174]. And the degradability is verified by the weight reduction of scaffolds after placed in culture mediums after some days. The hydrophilicity is confirmed by the contact angle of the materials. Through estimation of scaffold properties of the shape, connectivity, and biophysical and biochemical properties by different integrated technologies, and the verification by experiments, customized vascular scaffolds for cell growth and tissue formation will be ensured. However, usually scaffolds cannot be used in clinical immediately after preparation. There are required processes of cell culture for cell propagation and tissue maturation. During cell culture, microenvironments for cell growth and tissue formation (e.g. suitable temperature and certain nutritional conditions) need to be simulated and provided. Scaffolds are placed in incubators or bioreactors. It is worth noting that sterilization and contamination need to be considered during cell culture. After culture, the feasibility of clinical application is confirmed by observing the cell morphology, proliferation rate, chemical composition, and viability.

So far, animal experiments of vascular scaffolds have been done by researchers. Jiang et al. [72] prepared 3D printed prevascularized scaffolds using cell-laden AECM bioinks. The scaffolds are implanted into damaged hearts of mice. Experimental results show that vascularization was promoted, and myocardial hypertrophy and fibrosis were reduced. In addition to mice, rabbits [175] and pigs [176] were also evaluated in vivo. But there are differences between biological characteristics of these animals and humans. Syedain et al. [177] fabricated vascular scaffolds using fibrin gel loaded with fibroblasts. After the formation of blood vessel tissues, the vascular grafts were decellularized and implanted in a baboon. After a period of in vivo culture, negative effects include loss of burst strength, immune response and stenosis were not observed. Baboons have similar biological characteristics to humans. But experiments on such animals are limited by ethical issues and high costs. Yet experimental evaluation of scaffolds in primates is necessary before implantation in humans.

The possibility of clinical application of scaffold-based grafts is confirmed by animal experiments. But it's still preliminary transformation of vascular scaffolds to clinical productivity. The application of scaffold-based vascular tissue engineering is mainly concentrated in pre-clinical stages. There is a gap to general clinical application. A goal is to achieve completely biological off-the-shelf vascular scaffolds. Structures of vascular networks are diverse. And there are few universal standards for scaffold-based vascular grafts. Moreover, although implantation of scaffolds can be guided by surgical guide, positioning of scaffolds is still determined with the help of doctor's experience. Anatomical fit between scaffolds and human tissues at the implantation site is hard to be guaranteed. The development of precision medicine, robotics, and computer vision technology bring hopes to clinicians. Scaffold-based vascular tissue engineering is envisaged to be extensively used in clinical cases to meet the needs of tissue repair and organ replacement for individual patients.

\section{Future perspectives and conclusions}

Scaffold-based tissue engineering has made great progress. And 3D printing-based methods contribute to the biofabrication of blood vessels. Nevertheless, there is a bottleneck in printing functional vessels. Hindrances of modeling, composition design of inks, and preparation processes are involved. Future development may improve the situation with the aid of the following four aspects, including machine learning, nearinfrared photopolymerization, 4D printing, and combination of self-assembly and 3D printing-based methods.

First, the development of machine learning technology promotes its application in scaffold modeling and composition design of inks. It is difficult to fabricate vascular scaffolds of some complex tissues such as alveoli [79]. Even if they can be fabricated, cumbersome modeling and high time cost cannot achieve rapid rehearsal of clinical surgery and meet the urgent needs of patients. Alternative solutions are presented by machine learning. One goal of machine learning is to cre- 
ate an optimal model of vascular scaffolds, as discussed in the previous texts of scaffold modeling. Compared with parametric modeling and reverse engineering, shape of blood vessels is better fitted by this technique. The other goal is to design of composition of inks. Recently, through rheological analysis and rapid prototyping experiments, a database between process parameters and ink composition and mechanical strength was established by Sun et al. [178] But this process is relatively cumbersome. Sometimes both rheological analysis and experiments are necessary processes, but unnecessary experimental verification may be omitted by machine learning. For instance, the shape accuracy and extrudability of components with different concentrations can be studied through a few experiments [179]. On the basis, extrudability and shape accuracy may be predicted by establishing a functional relationship between component concentration and these parameters. After that, design of inks is simplified and oriented. Although there are few research reports in this filed, machine learning provides a promising way for fabricating vessels.

3D printing of vascular scaffolds by near-infrared photopolymerization is also an emerging research field. Generally, UV irradiation is not benefit to cell growth. But most of photosensitive materials are suitable for UV light. Near-infrared light improves the penetrability and the ranges of photopolymerization and printability of color structures [135]. Recently, the conversion of near-infrared light to UV light has been reported using up-conversion nanoparticles [106]. In particular, the feasibility of intravital 3D printing was provided by this method [44]. Up to now, patients are inevitably traumatized when implanting scaffolds by traditional methods. Based on the injection of print materials and photopolymerization of near-infrared light, a vascular scaffold may be directly fabricated in vivo. This intravital 3D printing technology is of landmark significance in tissue repair and organ replacement. But researches on 3D printing by near-infrared photopolymerization are still in infancy. There are some aspects for further studies, such as optimization of process parameters, material development, and building of devices. In addition to process parameters similar to UV-assisted 3D printing, the conversion rate of near-infrared light to UV, irradiation dose, and concentration of upconversion nanoparticles also need to be investigated. And commercial near-infrared light-assisted 3D printers are waiting to be available to promote researches in this field.

Application of 4D printing to prepare vascular scaffolds is one of the future directions. Compared with $3 \mathrm{D}$ printing, a characteristic of $4 \mathrm{D}$ printing is deformable structures under external stimulus (e.g. temperature, $\mathrm{pH}$, light, chemicals) [180]. This technology makes it possible to improve the accuracy and resolution of scaffolds because $4 \mathrm{D}$ printing may enable not only directly formation of vascular scaffolds through external stimulation, but also may shrink 3D printed scaffolds after post-processing [181, 182]. Spontaneous deformation of $4 \mathrm{D}$ printing is fascinated by many researchers [183]. For example, Zhao et al. [184] prepared vascular scaffolds with endothelial cells coating by a shape memory polymer. Transformation of the polymer from a planar structure to a 3D scaffold was created under a temperature field. Gong et al. [185] fabricated vascular scaffolds with a certain diameter through 3D printing of hydrogels. Then the diameter of the scaffolds was reduced by complexation reaction, leading to resolution enhancement of the 3D printed constructs. In 4D printing, material selection and structural design are the important factors to ensure a formation of scaffolds [186]. So, a feasible method of 4D printing is to print layered materials by using multi-jet 3D printing or multistep 3D printing processes. This technology is expected to be deeply applied, especially in fabrication of high-resolution structures.

Combination of self-assembly and 3D printing-based methods is a very promising research point, too. Cells are regulated at molecular and nanometer scale by selfassembly technologies, promoting vascularization and functionalization. And the preparation of vascular scaffolds from microscale to macroscale can be achieved by $3 \mathrm{D}$ printing. Shaped and functionalized vessels can be prepared by combining self-assembly and 3D printing-based approaches. Although this is a promising field, it is limited by current $3 \mathrm{D}$ printing processes. Combination of scaffold-free method and $3 \mathrm{D}$ printing technology has also been reported. Cell spheroids were placed and stacked on needles by Kenzan bioprinting method [187], and scaffold-free structures were fabricated following cell culture and needle removal. It is feasible to prepare simple vascular grafts by this method. But there exist difficulties in preparing complex vascular grafts. SkylarScott et al. [137] fabricated organ-specific tissues embedded with vascular channels by using cell aggregates as the support material. Cells with high density and viability were formed in 3D structures. This technology is similar to suspension 3D printing. But there exist cons of using cell aggregates or cell spheroids in the printing processes. Specially, the prepared blood vessels lack sufficient cell maturation and tissue function. With the additional advances of organ engineering such as organoids [188], complex vascular grafts may be prepared using this method.

To sum up, 3D printing has been extensively applied to the fabrication of vascular scaffolds to form new blood vessel tissues. In this review, the important subject of feasibility of the 3D printed vasculature scaffolds to form new blood vessel tissues in vivo is discussed. And modeling and fabrication methods for $3 \mathrm{D}$ printing of vascular scaffolds are presented. Modeling methods include parametric modeling and reverse engineering. 3D printing of vascular scaffolds is organized mainly by three points, extrusion-based 3D printing, inkjet 3D printing, and UV-assisted 3D printing. 
Specially, print materials for vascular scaffolds are elaborated. And superiorities and application fields of different modeling and fabrication methods are compared and discussed. To achieve high-precision fabrication of vascular scaffolds, preparation methods including commonly used integrated technologies are involved. Significance and future perspectives of scaffold-based vascular tissue engineering are also discussed. 3D printing of vascular scaffolds has shown a wide range of potential applications for tissue repair and organ replacement.

Acknowledgements This research is supported by the Innovative Public Service Center of High-End Manufacturing Technology for Technical Service of High-Tech Zone, Qiqihar, China.

Author contributions PJW contributed to writing —original draft; YZS helped in writing - review, supervision, and project administration; XQS contributed to conceptualization and review; HXS contributed to resources; HHN contributed to resources; HTL contributed to supervision, project administration and funding acquisition.

\section{Compliance with ethical standards}

Conflict of interest The authors declare no conflict of interest.

Ethical approval This study does not contain any studies with human or animal subjects performed by any of the authors.

\section{References}

1. Nie M, Takeuchi S (2018) Bottom-up biofabrication using microfluidic techniques. Biofabrication 10(4):044103. https://doi. org/10.1088/1758-5090/aadef9

2. Fang Y, Ouyang L, Zhang T et al (2020) Optimizing bifurcated channels within an anisotropic scaffold for engineering vascularized oriented tissues. Adv Healthc Mater 2000782. https://doi. org/10.1002/adhm.202000782

3. Attalla R, Puersten E, Jain N et al (2018) 3D bioprinting of heterogeneous bi- and tri-layered hollow channels within gel scaffolds using scalable multi-axial microfluidic extrusion nozzle. Biofabrication 11(1):015012. https://doi.org/10.1088/1758-5090/aaf7c7

4. Nurden AT (2011) Platelets, inflammation and tissue regeneration. Thromb Haemost 105(Suppl 1):S13-S33. https://doi.org/10.116 0/THS10-11-0720

5. Gu W, Hong X, Potter C et al (2017) Mesenchymal stem cells and vascular regeneration. Microcirculation 24(1):e12324. https://doi. org/10.1111/micc.12324

6. Carrabba M, Madeddu P (2018) Current strategies for the manufacture of small size tissue engineering vascular grafts. Front Bioeng Biotechnol 6:41. https://doi.org/10.3389/fbioe.2018.000 41

7. Groll J, Boland T, Blunk T et al (2016) Biofabrication: reappraising the definition of an evolving field. Biofabrication 8(1):013001. https://doi.org/10.1088/1758-5090/8/1/013001

8. Zhang WJ, Liu W, Cui L et al (2007) Tissue engineering of blood vessel. J Cell Mol Med 11(5):945-957. https://doi.org/10.1111/j. 1582-4934.2007.00099.x

9. Nakayama Y, Furukoshi M, Terazawa T (2019) Development of a long autologous small-caliber biotube vascular graft. Eur J Vasc
Endovasc Surg 58(6):e121. https://doi.org/10.1016/j.ejvs.2019.0 6.661

10. Aoki FG, Varma R, Marin-Araujo AE et al (2019) Deepithelialization of porcine tracheal allografts as an approach for tracheal tissue engineering. Sci Rep 9(1):1-12. https://doi.org/1 0.1038/s41598-019-48450-4

11. Song HHG, Rumma RT, Ozaki CK et al (2018) Vascular tissue engineering: progress, challenges, and clinical promise. Cell Stem Cell 22(3):340-354. https://doi.org/10.1016/j.stem.2018.02.009

12. Yin H, Du B, Chen Y et al (2020) Dual-encapsulated biodegradable 3D scaffold from liposome and waterborne polyurethane for local drug control release in breast cancer therapy. J Biomater Sci Polym Ed (just-accepted):1-18. https://doi.org/10.1080/0920506 3.2020 .1796230

13. Serbo JV, Gerecht S (2013) Vascular tissue engineering: biodegradable scaffold platforms to promote angiogenesis. Stem Cell Res Ther 4(1):8. https://doi.org/10.1186/scrt156

14. Bhatia SN, Ingber DE (2014) Microfluidic organs-on-chips. Nat Biotechnol 32(8):760-772. https://doi.org/10.1038/nbt.2989

15. Li X, Xu J, Nicolescu CT et al (2017) Generation, endothelialization, and microsurgical suture anastomosis of strong 1-mmdiameter collagen tubes. Tissue Eng Part A 23(7-8):335-344. https://doi.org/10.1089/ten.TEA.2016.0339

16. Du Y, Woo HK, Li L et al (2014) Effect of bi-directional microfabricated topographical cues on cellular behavior of mammalian cell line. Microelectron Eng 124:37-41. https://doi.org/10.1016/ j.mee.2014.04.010

17. Novak T, Fites Gilliland $\mathrm{K}, \mathrm{Xu} X$ et al (2016) In vivo cellular infiltration and remodeling in a decellularized ovine osteochondral allograft. Tissue Eng Part A 22(21-22):1274-1285. https:// doi.org/10.1089/ten.TEA.2016.0149

18. Li Y, Zhu T, Wang L et al (2020) Tissue-engineered decellularized allografts for anterior cruciate ligament reconstruction. ACS Biomater Sci Eng 6(10):5700-5710. https://doi.org/10.102 1/acsbiomaterials.0c00269

19. Huang J, Xia X, Zou Q et al (2019) The long-term behaviors and differences in bone reconstruction of three polymerbased scaffolds with different degradability. J Mater Chem B 7(48):7690-7703. https://doi.org/10.1039/C9TB02072A

20. Groll J, Burdick JA, Cho DW et al (2018) A definition of bioinks and their distinction from biomaterial inks. Biofabrication 11(1):013001. https://doi.org/10.1088/1758-5090/aaec52

21. Gungor-Ozkerim PS, Inci I, Zhang YS et al (2018) Bioinks for 3D bioprinting: an overview. Biomate Sci-UK 6(5):915-946. https:// doi.org/10.1039/C7BM00765E

22. Gao Q, Liu Z, Lin Z et al (2017) 3D bioprinting of vessel-like structures with multilevel fluidic channels. ACS Biomater Sci Eng 3(3):399-408. https://doi.org/10.1021/acsbiomaterials.6b00643

23. Shao L, Gao Q, Xie C et al (2020) Sacrificial microgel-laden bioink-enabled 3D bioprinting of mesoscale pore networks. BioDes Manuf 3:30-39. https://doi.org/10.1007/s42242-020-00062$\mathrm{y}$

24. Hsieh HY, Chu CW, Chiu MH et al (2017) Gradient strain chip for stimulating cellular behaviors in cell-laden hydrogel. J Vis Exp 126:e53715. https://doi.org/10.3791/53715

25. Hann SY, Cui H, Esworthy T et al (2019) Recent advances in 3D printing: vascular network for tissue and organ regeneration. Transl Res 211:46-63. https://doi.org/10.1016/j.trs1.2019.04.002

26. McCormack A, Highley CB, Leslie NR et al (2020) 3D printing in suspension baths: keeping the promises of bioprinting afloat. Trends Biotechnol 38(6):584-593. https://doi.org/10.101 6/j.tibtech.2019.12.020

27. Yu C, Schimelman J, Wang P et al (2020) Photopolymerizable biomaterials and light-based $3 \mathrm{D}$ printing strategies for biomedical applications. Chem Rev 120:10695-10743. https://doi.org/10.10 21/acs.chemrev.9b00810 
28. Wang K, Wang X, Han C et al (2017) From micro to macro: the hierarchical design in a micropatterned scaffold for cell assembling and transplantation. Adv Mater 29(2):1604600. https://doi. org/10.1002/adma.201604600

29. Huang K, Ozpinar EW, Su T et al (2020) An off-the-shelf artificial cardiac patch improves cardiac repair after myocardial infarction in rats and pigs. Sci Transl Med 12(538):eaat9683. https://doi.org/ 10.1126/scitranslmed.aat9683

30. Baudequin T, Tabrizian M (2018) Multilineage constructs for scaffold-based tissue engineering: a review of tissue-specific challenges. Adv Healthc Mater 7(3):1700734. https://doi.org/10.100 2/adhm.201700734

31. Gianni-Barrera R, Di Maggio N, Melly L et al (2020) Therapeutic vascularization in regenerative medicine. Stem Cell Transl Med 9(4):433-444. https://doi.org/10.1002/sctm.19-0319

32. Rieger J, Kaessmeyer S, Al Masri S et al (2020) Endothelial cells and angiogenesis in the horse in health and disease-a review. Anat Histol Embryol 49(5):656-678. https://doi.org/10.1111/ahe. 12588

33. Xing H, Lee H, Luo L et al (2020) Extracellular matrixderived biomaterials in engineering cell function. Biotechnol Adv 42:107421. https://doi.org/10.1016/j.biotechadv.2019.107421

34. Hong CA, Son HY, Nam YS (2018) Layer-by-layer sirna/poly(Llysine) multilayers on polydopamine-coated surface for efficient cell adhesion and gene silencing. Sci Rep 8(1):7738. https://doi. org/10.1038/s41598-018-25655-7

35. Sun L, Wang M, Chen S et al (2019) Molecularly engineered metal-based bioactive soft materials-neuroactive magnesium ion/polymer hybrids. Acta Biomater 85:310-319. https://doi.org/ 10.1016/j.actbio.2018.12.040

36. Lee SJ, Liu J, Oh SH et al (2008) Development of a composite vascular scaffolding system that withstands physiological vascular conditions. Biomaterials 29(19):2891-2898. https://doi.org/1 0.1016/j.biomaterials.2008.03.032

37. Chen C, Bai X, Ding Y et al (2019) Electrical stimulation as a novel tool for regulating cell behavior in tissue engineering. Biomater Res 23(1):25. https://doi.org/10.1186/s40824-019-017 6-8

38. Bracey DN, Seyler TM, Jinnah AH et al (2018) A decellularized porcine xenograft-derived bone scaffold for clinical use as a bone graft substitute: a critical evaluation of processing and structure. J Funct Biomater 9(3):45. https://doi.org/10.3390/jfb9030045

39. Shao Z, Vollrath F (2002) Surprising strength of silkworm silk. Nature 418(6899):741. https://doi.org/10.1038/418741a

40. Zhang K, Fu Q, Yoo J et al (2017) 3D bioprinting of urethra with PCL/PLCL blend and dual autologous cells in fibrin hydrogel: an in vitro evaluation of biomimetic mechanical property and cell growth environment. Acta Biomater 50(1):154-164. https://doi. org/10.1016/j.actbio.2016.12.008

41. VandeVord PJ, Matthew HWT, DeSilva SP et al (2002) Evaluation of the biocompatibility of a chitosan scaffold in mice. J Biomed Mater Res 59(3):585-590. https://doi.org/10.1002/jbm.1270

42. Anderson D, Pohan G, Raman J et al (2018) Improving surgical methods for studying vascular grafts in animal models. Tissue Eng Part C-Me 24(8):457-464. https://doi.org/10.1089/ten.TEC. 2018.0099

43. Wu Y, Ravnic DJ, Ozbolat IT (2020) Intraoperative bioprinting: repairing tissues and organs in a surgical setting. Trends Biotechnol 38(6):594-605. https://doi.org/10.1016/j.tibtech.2020.01.004

44. Urciuolo A, Poli I, Brandolino L et al (2020) Intravital threedimensional bioprinting. Nat. Biomed Eng 4:1-15. https://doi. org/10.1038/s41551-020-0568-Z

45. Szafron JM, Ramachandra AB, Breuer CK et al (2019) Optimization of tissue-engineered vascular graft design using computational modeling. Tissue Eng Part C-Me 25(10):561-570. https:// doi.org/10.1089/ten.TEC.2019.0086
46. Tu S, Hu F, Cai W et al (2017) Visualizing polymeric bioresorbable scaffolds with three-dimensional image reconstruction using contrast-enhanced micro-computed tomography. Int J Cardiovas Imaging 33(5):731-737. https://doi.org/10.1007/s10554-0 16-1049-Z

47. Wang ZJ, Zhu XW, Huang QT et al (2016) Three-dimensional reconstruction of human placental vascular network using in vitro mri data. Ultrasound Obstet Gyn 47(6):790-792. https://doi.org/ 10.1002/uog. 15809

48. Ozbolat V, Dey M, Ayan B et al (2019) Extrusion-based printing of sacrificial carbopol ink for fabrication of microfluidic devices. Biofabrication 11(3):034101. https://doi.org/10.1088/1758-5090/ ab10ae

49. Gao Q, Zhao P, Zhou R et al (2019) Rapid assembling organ prototypes with controllable cell-laden multi-scale sheets. BioDes Manuf 2(1):1-9. https://doi.org/10.1007/s42242-019-00032$\mathrm{Z}$

50. Nie J, Gao Q, Qiu JJ et al (2018) 3D printed lego((r))-like modular microfluidic devices based on capillary driving. Biofabrication 10(3):035001. https://doi.org/10.1088/1758-5090/aaadd3

51. Kruse CR, Singh M, Targosinski S et al (2017) The effect of ph on cell viability, cell migration, cell proliferation, wound closure, and wound reepithelialization: in vitro and in vivo study. Wound Repair Regen 25(2):260-269. https://doi.org/10.1111/wrr.12526

52. Yao T, Asayama Y (2017) Animal-cell culture media: history, characteristics, and current issues. Reprod Med Biol 16(2):99-117. https://doi.org/10.1002/rmb2.12024

53. Gao Q, He Y, Fu JZ et al (2015) Coaxial nozzle-assisted 3D bioprinting with built-in microchannels for nutrients delivery. Biomaterials 61:203-215. https://doi.org/10.1016/j.biomaterials. 2015.05.031

54. Ning L, Chen X (2017) A brief review of extrusion-based tissue scaffold bio-printing. Biotechnol J 12(8):1600671. https://doi.org/ 10.1002/biot.201600671

55. Kim S, Lee H, Chung $M$ et al (2013) Engineering of functional, perfusable 3D microvascular networks on a chip. Lab Chip 13(8):1489-1500. https://doi.org/10.1039/c3lc41320a

56. Vining KH, Mooney DJ (2017) Mechanical forces direct stem cell behaviour in development and regeneration. Nat Rev Mol Cell Bio 18(12):728-742. https://doi.org/10.1038/nrm.2017.108

57. Shao C, Chi J, Zhang H et al (2020) Development of cell spheroids by advanced technologies. Adv Mater Technol-US 5(9):2000183. https://doi.org/10.1002/admt.202000183

58. Fanous MJ, Li Y, Kandel ME et al (2019) Effects of substrate patterning on cellular spheroid growth and dynamics measured by gradient light interference microscopy (GLIM). J Biophotonics 12(12):e201900178. https://doi.org/10.1002/jbio.201900178

59. Huang YL, Ma Y, Wu C et al (2020) Tumor spheroids under perfusion within a 3D microfluidic platform reveal critical roles of cell-cell adhesion in tumor invasion. Sci Rep 10(1):9648. https:// doi.org/10.1038/s41598-020-66528-2

60. Zhao L, Xiu J, Liu Y et al (2019) A 3D printed hanging drop dripper for tumor spheroids analysis without recovery. Sci Rep 9(1):19717. https://doi.org/10.1038/s41598-019-56241-0

61. Jiang T, Munguia-Lopez J, Flores-Torres S et al (2018) Bioprintable alginate/gelatin hydrogel 3D in vitro model systems induce cell spheroid formation. J Vis Exp 137:e57826. https://doi.org/1 $0.3791 / 57826$

62. Dong X, Yuan X, Wang L et al (2018) Construction of a bilayered vascular graft with smooth internal surface for improved hemocompatibility and endothelial cell monolayer formation. Biomaterials 181:1-14. https://doi.org/10.1016/j.biomaterials.20 18.07.027

63. Gao Q, Xie C, Wang P et al (2020) 3D printed multi-scale scaffolds with ultrafine fibers for providing excellent biocompatibility. 
Mater Sci Eng C 107:110269. https://doi.org/10.1016/j.msec.201 9.110269

64. Wang P, Wang S (2020) Computer-aided ct image processing and modeling method for tibia microstructure. Bio-Des Manuf 3(1):71-82. https://doi.org/10.1007/s42242-020-00063-x

65. Kadkhodapour J, Montazerian H, Raeisi S (2014) Investigating internal architecture effect in plastic deformation and failure for tpms-based scaffolds using simulation methods and experimental procedure. Mater Sci Eng C 43:587-597. https://doi.org/10.101 6/j.msec.2014.07.047

66. Kriegman S, Blackiston D, Levin M et al (2020) A scalable pipeline for designing reconfigurable organisms. Proc Natl Acad Sci USA 117(4):1853-1859. https://doi.org/10.1073/pnas.19108 37117

67. Xu H-M, Wang Y-L, Jin H-M et al (2017) A novel micro-CTbased method to monitor the morphology of blood vessels in the rabbit endplate. Eur Spine J 26(1):221-227. https://doi.org/10.10 07/s00586-016-4849-x

68. Qiu Y, Myers DR, Lam WA (2019) The biophysics and mechanics of blood from a materials perspective. Nat Rev Mater 4(5):294-311. https://doi.org/10.1038/s41578-019-0099-y

69. Milleret V, Hefti T, Hall H et al (2012) Influence of the fiber diameter and surface roughness of electrospun vascular grafts on blood activation. Acta Biomater 8(12):4349-4356. https://doi.org/10.1 016/j.actbio.2012.07.032

70. Jungst T, Pennings I, Schmitz M et al (2019) Heterotypic scaffold design orchestrates primary cell organization and phenotypes in cocultured small diameter vascular grafts. Adv Funct Mater 29(43):1905987. https://doi.org/10.1002/adfm.201905987

71. Jordahl S, Solorio L, Neale DB et al (2019) Engineered fibrillar fibronectin networks as three-dimensional tissue scaffolds. Adv Mater 31(46):1904580. https://doi.org/10.1002/adma.201904580

72. Jang J, Park HJ, Kim SW et al (2017) 3D printed complex tissue construct using stem cell-laden decellularized extracellular matrix bioinks for cardiac repair. Biomaterials 112:264-274. https://doi. org/10.1016/j.biomaterials.2016.10.026

73. Wang Y, Kankala RK, Zhu K et al (2019) Coaxial extrusion of tubular tissue constructs using a gelatin/gelma blend bioink. ACS Biomater Sci Eng 5(10):5514-5524. https://doi.org/10.102 1/acsbiomaterials.9b00926

74. Kim SH, Yeon YK, Lee JM et al (2018) Precisely printable and biocompatible silk fibroin bioink for digital light processing 3D printing. Nat Commun 9(1):1620. https://doi.org/10.1038/s4146 7-018-03759-y

75. Wang L, Song D, Zhang X et al (2019) Silk-graphene hybrid hydrogels with multiple cues to induce nerve cell behavior. ACS Biomater Sci Eng 5(2):613-622. https://doi.org/10.1021/ acsbiomaterials. $8 \mathrm{~b} 01481$

76. Jeon S, Subbiah R, Bonaedy T et al (2018) Surface functionalized magnetic nanoparticles shift cell behavior with on/off magnetic fields. J Cell Physiol 233(2):1168-1178. https://doi.org/10.1002/ jcp. 25980

77. Liu H, Kitano S, Irie S et al (2020) Collagen microfibers induce blood capillary orientation and open vascular lumen. Adv Biosyst 4(5):2000038. https://doi.org/10.1002/adbi.202000038

78. Liu F, Liao X, Liu C et al (2020) Poly(l-lactide-cocaprolactone)/tussah silk fibroin nanofiber vascular scaffolds with small diameter fabricated by core-spun electrospinning technology. J Mater Sci 55(1):7106-7119. https://doi.org/10.1007/s 1085 3-020-04510-z

79. Grigoryan B, Paulsen SJ, Corbett DC et al (2019) Multivascular networks and functional intravascular topologies within biocompatible hydrogels. Science 364(6439):458-464. https://doi.org/1 0.1126/science.aav9750

80. Andrique L, Recher G, Alessandri K et al (2019) A model of guided cell self-organization for rapid and spontaneous formation of functional vessels. Sci Adv 5(6):eaau6562. https://doi.org/10. 1126/sciadv.aau6562

81. Lei D, Yang Y, Liu Z et al (2019) A general strategy of 3D printing thermosets for diverse applications. Mater Horiz 6(2):394-404. https://doi.org/10.1039/C8MH00937F

82. Lei D, Yang Y, Liu Z et al (2019) 3D printing of biomimetic vasculature for tissue regeneration. Mater Horiz 6(6):1197-1206. https://doi.org/10.1039/C9MH00174C

83. Wang W, Nie W, Zhou X et al (2018) Fabrication of heterogeneous porous bilayered nanofibrous vascular grafts by two-step phase separation technique. Acta Biomater 79:168-181. https://doi.org/ 10.1016/j.actbio.2018.08.014

84. Hewes S, Wong AD, Searson PC (2017) Bioprinting microvessels using an inkjet printer. Bioprinting 7:14-18. https://doi.org/10.10 16/j.bprint.2017.05.002

85. Gao G, Park JY, Kim BS et al (2018) Coaxial cell printing of freestanding, perfusable, and functional in vitro vascular models for recapitulation of native vascular endothelium pathophysiology. Adv Healthc Mater 7(23):1801102. https://doi.org/10.1002/ adhm.201801102

86. Liu W, Zhong Z, Hu N et al (2018) Coaxial extrusion bioprinting of $3 \mathrm{D}$ microfibrous constructs with cell-favorable gelatin methacryloyl microenvironments. Biofabrication 10(2):024102. https://doi.org/10.1088/1758-5090/aa9d44

87. Axpe E, Oyen ML (2016) Applications of alginate-based bioinks in 3D bioprinting. Int J Mol Sci 17(12):1976. https://doi.org/10.3 390/ijms 17121976

88. Li H, Li N, Zhang H et al (2020) Three-dimensional bioprinting of perfusable hierarchical microchannels with alginate and silk fibroin double cross-linked network. 3D Print Addit Manuf 7(2):78-84. https://doi.org/10.1089/3dp.2019.0115

89. Hammer J, Han LH, Tong X et al (2014) A facile method to fabricate hydrogels with microchannel-like porosity for tissue engineering. Tissue Eng Part C-Me 20(2):169-176. https://doi. org/10.1089/ten.TEC.2013.0176

90. Kim MH, Nam SY (2020) Assessment of coaxial printability for extrusion-based bioprinting of alginate-based tubular constructs. Bioprinting 20:e0092. https://doi.org/10.1016/j.bprint.2020.e00 092

91. Kjar A, McFarland B, Mecham K et al (2021) Engineering of tissue constructs using coaxial bioprinting. Bioact Mater 6(2):460-471. https://doi.org/10.1016/j.bioactmat.2020.08.020

92. Zhao H, Chen Y, Shao L et al (2018) Airflow-assisted 3D bioprinting of human heterogeneous microspheroidal organoids with microfluidic nozzle. Small 14(39):1802630.https://doi.org/10.10 02/smll.201802630

93. Skylar-Scott MA, Mueller J, Visser CW et al (2019) Voxelated soft matter via multimaterial multinozzle 3D printing. Nature 575(7782):330-335.https://doi.org/10.1038/s41586-019-1736-8

94. Melo BAG, Jodat YA, Mehrotra S et al (2019) 3D printed cartilage-like tissue constructs with spatially controlled mechanical properties. Adv Funct Mater 29(51):1906330. https://doi.org/ 10.1002/adfm.201906330

95. Li L, Qin S, Peng J et al (2020) Engineering gelatin-based alginate/carbon nanotubes blend bioink for direct 3D printing of vessel constructs. Int J Biol Macromol 145:262-271. https://doi. org/10.1016/j.ijbiomac.2019.12.174

96. Jin Y, Du J, Ma Z et al (2017) An optimization approach for path planning of high-quality and uniform additive manufacturing. Int J Adv Manuf Technol 92(1-4):651-662.https://doi.org/10.1007/ s00170-017-0207-3

97. Jin Y, Zhao D, Huang Y (2018) Study of extrudability and standoff distance effect during nanoclay-enabled direct printing. Bio-Des Manuf 1(2):123-134. https://doi.org/10.1007/s42242-018-0009y 
98. Christensen K, Zhang Z, Xu C et al (2018) Deformation compensation during buoyancy-enabled inkjet printing of three-dimensional soft tubular structures. J Manuf Sci Eng 140(1):011011. https://doi.org/10.1115/1.4037996

99. Lv S, Nie J, Gao Q et al (2020) Micro/nanofabrication of brittle hydrogels using 3D printed soft ultrafine fiber molds for damagefree demolding. Biofabrication 12(2):025015. https://doi.org/10. 1088/1758-5090/ab57d8

100. Liashenko I, Rosell-Llompart J, Cabot A (2020) Ultrafast 3D printing with submicrometer features using electrostatic jet deflection. Nat Commun 11(1):1-9. https://doi.org/10.1038/s41467-02 0-14557-w

101. Li Y, Mao Q, Li X et al (2019) High-fidelity and high-efficiency additive manufacturing using tunable pre-curing digital light processing. Addit Manuf 30:100889. https://doi.org/10.1016/j. addma.2019.100889

102. Wadnap S, Krishnamoorthy S, Zhang Zet al (2019) Biofabrication of 3D cell-encapsulated tubular constructs using dynamic optical projection stereolithography. J Mater Sci Mater Med 30(3):36. https://doi.org/10.1007/s10856-019-6239-5

103. Wang P, Berry D, Moran A et al (2019) Controlled growth factor release in 3D-printed hydrogels. Adv Healthc Mater 9(15):1900977.https://doi.org/10.1002/adhm.201900977

104. Kelly BE, Bhattacharya I, Heidari H et al (2019) Volumetric additive manufacturing via tomographic reconstruction. Science 363(6431):1075-1079. https://doi.org/10.1126/science.aau7114

105. Loterie D, Delrot P, Moser C (2020) High-resolution tomographic volumetric additive manufacturing. Nat Commun 11(1):852. https://doi.org/10.1038/s41467-020-14630-4

106. Chen Y, Zhang J, Liu X et al (2020) Noninvasive in vivo 3D bioprinting. Sci Adv 6(23):eaba7406. https://doi.org/10.1126/sciadv. aba7406

107. Wang Z, Kumar H, Tian Z et al (2018) Visible light photoinitiation of cell-adhesive gelatin methacryloyl hydrogels for stereolithography 3D bioprinting. ACS Appl Mater Interfaces 10(32):26859-26869. https://doi.org/10.1021/acsami.8b06607

108. Yi H-G, Jeong YH, Kim Y et al (2019) A bioprinted humanglioblastoma-on-a-chip for the identification of patient-specific responses to chemoradiotherapy. Nat Biomed Eng 3(7):509-519. https://doi.org/10.1038/s41551-019-0363-x

109. Attalla R, Ling C, Selvaganapathy P (2016) Fabrication and characterization of gels with integrated channels using 3D printing with microfluidic nozzle for tissue engineering applications. Biomed Microdev 18(1):17. https://doi.org/10.1007/s10544-0160042-6

110. Shao L, Gao Q, Xie C et al (2020) Synchronous 3D bioprinting of large-scale cell-laden constructs with nutrient networks. Adv Healthc Mater 9(15):1901142. https://doi.org/10.1002/adhm.201 901142

111. Li S, Liu Y, Li Y et al (2016) A novel method for fabricating engineered structures with branched micro-channel using hollow hydrogel fibers. Biomicrofluidics 10(6):064104. https://doi.org/1 $0.1063 / 1.4967456$

112. Chen R, Grindrod S, Yu I (2020) Controllability over wall thickness of tubular structures and encapsulation during co-axial extrusion of a thermal-crosslinking hydrogel. J Manuf Sci Eng 142(8):081006. https://doi.org/10.1115/1.4047091

113. Milojevic M, Vihar B, Banovic L et al (2019) Core/shell printing scaffolds for tissue engineering of tubular structures. J Vis Exp 151:e59951. https://doi.org/10.3791/59951

114. Liang Q, Gao F, Zeng Z et al (2020) Coaxial scale-up printing of diameter-tunable biohybrid hydrogel microtubes with high strength, perfusability, and endothelialization. Adv Funct Mater 30:2001485. https://doi.org/10.1002/adfm.202001485

115. Faramarzi N, Yazdi IK, Nabavinia M et al (2018) Patient-specific bioinks for 3D bioprinting of tissue engineering scaffolds. Adv
Healthc Mater 7(11):1701347. https://doi.org/10.1002/adhm.201 701347

116. Christensen K, Xu C, Chai W et al (2015) Freeform inkjet printing of cellular structures with bifurcations. Biotechnol Bioeng 112(5):1047-1055. https://doi.org/10.1002/bit.25501

117. Xu C, Chai W, Huang Y et al (2012) Scaffold-free inkjet printing of three-dimensional zigzag cellular tubes. Biotechnol Bioeng 109(12):3152-3160. https://doi.org/10.1002/bit.24591

118. Nishiyama Y, Nakamura M, Henmi C et al (2009) Development of a three-dimensional bioprinter: construction of cell supporting structures using hydrogel and state-of-the-art inkjet technology. J Biomech Eng 131(3):035001. https://doi.org/10.1115/1.3002759

119. Nishiyama Y, Henmi C, Iwanaga $S$ et al (2008) Ink jet threedimensional digital fabrication for biological tissue manufacturing: analysis of alginate microgel beads produced by ink jet droplets for three dimensional tissue fabrication. J Imaging Sci Technol 52(6):060201. https://doi.org/10.2352/J.ImagingSci. Technol.(2008)52:6(060201)

120. Pataky K, Braschler T, Negro A et al (2012) Microdrop printing of hydrogel bioinks into 3D tissue-like geometries. Adv Mater 24(3):391-396. https://doi.org/10.1002/adma.201102800

121. Altun E, Ekren N, Kuruca SE et al (2019) Cell studies on electrohydrodynamic (EHD)-3D-bioprinted bacterial celluloselpolycaprolactone scaffolds for tissue engineering. Mater Lett 234:163-167. https://doi.org/10.1016/j.matlet.2018.09.085

122. Cui X, Boland T (2009) Human microvasculature fabrication using thermal inkjet printing technology. Biomaterials 30(31):6221-6227. https://doi.org/10.1016/j.biomaterials.2009.0 7.056

123. Vijayavenkataraman S, Thaharah S, Zhang S et al (2019) Electrohydrodynamic jet 3D-printed PCL/PAA conductive scaffolds with tunable biodegradability as nerve guide conduits (NGCs) for peripheral nerve injury repair. Mater Des 162:171-184. https:// doi.org/10.1016/j.matdes.2018.11.044

124. Wang L, Luo Y, Ahmad Z et al (2018) Fabrication of stacked-ring netted tubular constructs via 3D template electrohydrodynamic printing. J Mater Sci 53(17):11943-11950. https://doi.org/10.10 07/s10853-018-2468-0

125. Krishnamoorthy S, Wadnap S, Noorani B et al (2020) Investigation of gelatin methacrylate working curves in dynamic optical projection stereolithography of vascular-like constructs. Eur Polym J 124:109487. https://doi.org/10.1016/j.eurpolymj.20 20.109487

126. Zhang R, Larsen NB (2017) Stereolithographic hydrogel printing of 3D culture chips with biofunctionalized complex 3D perfusion networks. Lab Chip 17(24):4273-4282. https://doi.org/10.1039/ c7lc00926g

127. Xue D, Wang Y, Zhang J et al (2018) Projection-based 3D printing of cell patterning scaffolds with multiscale channels. ACS Appl Mater Interfaces 10(23):19428-19435. https://doi.org/10.1 021/acsami.8b03867

128. Zhang AP, Qu X, Soman P et al (2012) Rapid fabrication of complex 3D extracellular microenvironments by dynamic optical projection stereolithography. Adv Mater 24(31):4266-4270. https://doi.org/10.1002/adma.201202024

129. Chiu Y-C, Shen Y-F, Alvin L et al (2019) 3D printing of amino resin-based photosensitive materials on multi-parameter optimization design for vascular engineering applications. Polymers 11(9):1394. https://doi.org/10.3390/polym11091394

130. Yu C, Ma X, Zhu W et al (2019) Scanningless and continuous 3D bioprinting of human tissues with decellularized extracellular matrix. Biomaterials 194:1-13. https://doi.org/10.1016/j. biomaterials.2018.12.009

131. Shin S, Kwak H, Hyun J (2018) Melanin nanoparticleincorporated silk fibroin hydrogels for the enhancement of printing resolution in 3D-projection stereolithography of 
poly(ethylene glycol)-tetraacrylate bio-ink. ACS Appl Mater Interfaces 10(28):23573-23582. https://doi.org/10.1021/acsami. $8 \mathrm{~b} 05963$

132. Zhu W, Qu X, Zhu J et al (2017) Direct 3D bioprinting of prevascularized tissue constructs with complex microarchitecture. Biomaterials 124:106-115. https://doi.org/10.1016/j.biomaterials.20 17.01 .042

133. Ware HOT, Farsheed AC, Akar B et al (2018) High-speed ondemand 3D printed bioresorbable vascular scaffolds. Mater Today Chem 7:25-34. https://doi.org/10.1016/j.mtchem.2017.10.002

134. Bernal PN, Delrot P, Loterie D et al (2019) Volumetric bioprinting of complex living-tissue constructs within seconds. Adv Mater 31(42):1904209. https://doi.org/10.1002/adma.201904209

135. Zhu J, Zhang Q, Yang T et al (2020) 3D printing of multi-scalable structures via high penetration near-infrared photopolymerization. Nat Commun 11(1):3462. https://doi.org/10.1038/s41467020-17251-z

136. Nie J, Gao Q, Xie C et al (2020) Construction of multi-scale vascular chips and modelling of the interaction between tumours and blood vessels. Mater Horiz 7(1):82-92. https://doi.org/10.10 39/C9MH01283D

137. Skylar-Scott MA, Uzel SGM, Nam LL et al (2019) Biomanufacturing of organ-specific tissues with high cellular density and embedded vascular channels. Sci Adv 5(9):eaaw2459. https://doi. org/10.1126/sciadv.aaw2459

138. Huling J, Ko IK, Atala A et al (2016) Fabrication of biomimetic vascular scaffolds for 3D tissue constructs using vascular corrosion casts. Acta Biomater 32:190-197. https://doi.org/10.1016/j. actbio.2016.01.005

139. Yuan J, Qing G, Chaoqi X et al (2020) Fabrication of heterogeneous scaffolds using melt electrospinning writing: design and optimization. Mater Design 185:108274. https://doi.org/10.1016/ j.matdes.2019.108274

140. Castilho M, van Mil A, Maher M et al (2018) Melt electrowriting allows tailored microstructural and mechanical design of scaffolds to advance functional human myocardial tissue formation. Adv Funct Mater 28(40):1803151. https://doi.org/10.1002/adfm.2018 03151

141. Pensa NW, Curry AS, Bonvallet PP et al (2019) 3D printed mesh reinforcements enhance the mechanical properties of electrospun scaffolds. Biomater Res 23:22. https://doi.org/10.1186/s40824-0 19-0171-0

142. Yeo M, Kim G (2020) Micro/nano-hierarchical scaffold fabricated using a cell electrospinning/3D printing process for co-culturing myoblasts and huvecs to induce myoblast alignment and differentiation. Acta Biomater 107:102-114. https://doi.org/10.1016/j. actbio.2020.02.042

143. Huang R, Gao X, Wang J et al (2018) Triple-layer vascular grafts fabricated by combined e-jet 3D printing and electrospinning. Ann Biomed Eng 46(9):1254-1266. https://doi.org/10.1007/s10439-0 18-2065-Z

144. Wu Y, Fuh J, Wong YS et al (2017) A hybrid electrospinning and electrospraying 3D printing for tissue engineered scaffolds. Rapid Prototyping J 23(6):1011-1019. https://doi.org/10.1108/rpj-08-2 015-0111

145. Lee SJ, Nowicki M, Harris B et al (2017) Fabrication of a highly aligned neural scaffold via a table top stereolithography $3 \mathrm{D}$ printing and electrospinning. Tissue Eng Part A 23(11-12):491-502. https://doi.org/10.1089/ten.tea.2016.0353

146. Clohessy RM, Cohen DJ, Stumbraite K et al (2020) In vivo evaluation of an electrospun and 3D printed cellular delivery device for dermal wound healing. J Biomed Mater Res B Appl Biomater 108(6):2560-2570. https://doi.org/10.1002/jbm.b.34587

147. Tsuda S, Jaffery H, Doran D et al (2015) Customizable 3D printed 'plug and play' millifluidic devices for programmable fluidics. PLoS ONE 10(11):e0141640. https://doi.org/10.1371/ journal.pone. 0141640

148. Vittayarukskul K, Lee AP (2017) A truly lego ${ }^{\circledR}{ }_{\text {-like modular }}$ microfluidics platform. J Micromech Microeng 27(3):035004. https://doi.org/10.1088/1361-6439/aa53ed

149. Subbiah R, Hipfinger C, Tahayeri A et al (2020) 3D printing of microgel-loaded modular microcages as instructive scaffolds for tissue engineering. Adv Mater 32:2001736. https://doi.org/10.10 02/adma.202001736

150. Valentin TM, DuBois EM, Machnicki CE et al (2019) 3D printed self-adhesive PEGDA-PAA hydrogels as modular components for soft actuators and microfluidics. Polym Chem 10(16):2015-2028. https://doi.org/10.1039/C9PY00211A

151. Qiu J, Gao Q, Zhao H et al (2017) Rapid customization of 3D integrated microfluidic chips via modular structure-based design. ACS Biomater Sci Eng 3(10):2606-2616. https://doi.org/10.102 1/acsbiomaterials.7b00401

152. Zhu Q, Hamilton M, Vasquez B et al (2019) 3D-printing enabled micro-assembly of a microfluidic electroporation system for 3D tissue engineering. Lab Chip 19(14):2362-2372. https://doi.org/ 10.1039/C9LC00046A

153. Lee Y, Kim B, Oh I et al (2018) Optofluidic modular blocks for on-demand and open-source prototyping of microfluidic systems. Small 14(52):1802769. https://doi.org/10.1002/smll.201802769

154. Yang K, Xia Y, Li L et al (2018) Experimental study on hybrid machining of laser irradiation and grinding for sharpening of a CVD diamond micro-milling tool. Int J Adv Manuf Technol 96(1):327-336. https://doi.org/10.1007/s00170-018-1624-7

155. Xia H, Zhao D, Zhu H et al (2018) Lyophilized scaffolds fabricated from 3D-printed photocurable natural hydrogel for cartilage regeneration. ACS Appl Mater Interfaces 10(37):31704-31715. https://doi.org/10.1021/acsami.8b10926

156. Jensen T, Wanczyk H, Sharma I et al (2019) Polyurethane scaffolds seeded with autologous cells can regenerate long esophageal gaps: an esophageal atresia treatment model. J Pediatr Surg 54(9):1744-1754. https://doi.org/10.1016/j.jpedsurg.2018.09.02 4

157. Zhang B, Gao L, Gu L et al (2017) High-resolution 3D bioprinting system for fabricating cell-laden hydrogel scaffolds with high cellular activities. Procedia CIRP 65:219-224. https://doi.org/10. 1016/j.procir.2017.04.017

158. Ahlfeld T, Cidonio G, Kilian D et al (2017) Development of a clay based bioink for 3D cell printing for skeletal application. Biofabrication 9(3):034103. https://doi.org/10.1088/1758-5090/aa7e96

159. Thornton SC, Mueller SN, Levine EM (1983) Human endothelial cells: use of heparin in cloning and long-term serial cultivation. Science 222(4624):623-625. https://doi.org/10.1126/science.663 5659

160. Koller GM, Schafer C, Kemp SS et al (2020) Proinflammatory mediators, il (interleukin)- $1 \beta$, TNF (tumor necrosis factor) $\alpha$, and thrombin directly induce capillary tube regression. Arterioscl Throm Vas 40(2):365-377. https://doi.org/10.1161/ATVBAHA. 119.313536

161. Turner CJ, Badu-Nkansah K, Hynes RO (2017) Endotheliumderived fibronectin regulates neonatal vascular morphogenesis in an autocrine fashion. Angiogenesis 20(4):519-531. https://doi. org/10.1007/s10456-017-9563-8

162. Hofmann A, Ritz U, Verrier S et al (2008) The effect of human osteoblasts on proliferation and neo-vessel formation of human umbilical vein endothelial cells in a long-term 3D co-culture on polyurethane scaffolds. Biomaterials 29(31):4217-4226. https:// doi.org/10.1016/j.biomaterials.2008.07.024

163. Salahuddin SZ, Nakamura S, Biberfeld P et al (1988) Angiogenic properties of Kaposi's sarcoma-derived cells after long-term culture in vitro. Science 242(4877):430-433. https://doi.org/10.112 6/science. 2459779 
164. Li Y, Li X, Chen C et al (2016) A rapid, non-invasive and non-destructive method for studying swelling behavior and microstructure variations of hydrogels. Carbohyd Polym 151:1251-1260. https://doi.org/10.1016/j.carbpol.2016.06.054

165. Hu C, Chen Y, Tan MJA et al (2019) Microfluidic technologies for vasculature biomimicry. Analyst 144(15):4461-4471. https:// doi.org/10.1039/C9AN00421A

166. Varga Z, Flammer AJ, Steiger P et al (2020) Endothelial cell infection and endotheliitis in COVID-19. The Lancet 395(10234):1417-1418. https://doi.org/10.1016/S0140-6736(20 30937-5

167. Hall GN, Mendes LF, Gklava C et al (2020) Developmentally engineered callus organoid bioassemblies exhibit predictive in vivo long bone healing. Adv Sci 7(2):1902295. https://doi.org/ 10.1002/advs.201902295

168. Zohra FT, Medved M, Lazareva N et al (2015) Functional behavior and gene expression of magnetic nanoparticle-loaded primary endothelial cells for targeting vascular stents. Nanomedicine 10(9):1391-1406. https://doi.org/10.2217/nnm.15.13

169. Gao Q, Li X, Yu W et al (2020) Fabrication of mixed-charge polypeptide coating for enhanced hemocompatibility and antiinfective effect. ACS Appl Mater Interfaces 12(2):2999-3010. https://doi.org/10.1021/acsami.9b19335

170. Walker BW, Lara RP, $\mathrm{Yu} \mathrm{CH}$ et al (2019) Engineering a naturally-derived adhesive and conductive cardiopatch. Biomaterials 207:89-101. https://doi.org/10.1016/j.biomaterials.2019.0 3.015

171. Shen J, Ji Y, Xie M et al (2020) Cell-modified bioprinted microspheres for vascular regeneration. Mater Sci Eng C 112:110896. https://doi.org/10.1016/j.msec.2020.110896

172. Zhu M, Li W, Dong X et al (2019) In vivo engineered extracellular matrix scaffolds with instructive niches for oriented tissue regeneration. Nat Commun 10(1):4620. https://doi.org/10.1038/ s41467-019-12545-3

173. Redd MA, Zeinstra N, Qin W et al (2019) Patterned human microvascular grafts enable rapid vascularization and increase perfusion in infarcted rat hearts. Nat Commun 10(1):584. https:// doi.org/10.1038/s41467-019-08388-7

174. Zhou L, Ramezani H, Sun M et al (2020) 3D printing of high strength chitosan hydrogel scaffolds without any organic solvents. Biomater Sci-UK 8:5020-5028. https://doi.org/10.1039/D0BM0 0896F

175. Guo X, Zhu J, Zhang $\mathrm{H}$ et al (2019) Facile preparation of a controlled-release tubular scaffold for blood vessel implantation. J Colloid Interf Sci 539:351-360. https://doi.org/10.1016/j.jcis.2 018.12.086
176. Swim MM, Albertario A, Iacobazzi D et al (2019) Amnion-based scaffold with enhanced strength and biocompatibility for in vivo vascular repair. Tissue Eng Part A 25(7-8):603-619. https://doi. org/10.1089/ten.TEA.2018.0175

177. Syedain ZH, Graham ML, Dunn TB et al (2017) A completely biological "off-the-shelf" arteriovenous graft that recellularizes in baboons. Sci Transl Med 9(414):eaan4209. https://doi.org/10.11 26/scitranslmed.aan4209

178. Sun Y, Yu K, Nie J et al (2020) Modeling the printability of photocuring and strength adjustable hydrogel bioink during projection based 3D bioprinting. Biofabrication. https://doi.org/10.1088/17 58-5090/aba413

179. Lee J, Oh SJ, An SH et al (2020) Machine learning-based design strategy for 3D printable bioink: elastic modulus and yield stress determine printability. Biofabrication 12(3):035018. https://doi. org/10.1088/1758-5090/ab8707

180. Momeni F, Liu X, Ni J et al (2017) A review of 4D printing. Mater Design 122:42-79. https://doi.org/10.1016/j.matdes.2017.02.068

181. González-Henríquez CM, Sarabia-Vallejos MA, RodriguezHernandez J (2019) Polymers for additive manufacturing and 4D-printing: materials, methodologies, and biomedical applications. Prog Polym Sci 94:57-116. https://doi.org/10.1016/j. progpolymsci.2019.03.001

182. Lin C, Zhang L, Liu Y et al (2020) 4D printing of personalized shape memory polymer vascular stents with negative poisson's ratio structure: a preliminary study. Sci China Technol Sci 63(4):578-588. https://doi.org/10.1007/s11431-019-146 $8-2$

183. Joshi S, Rawat K, Karunakaran C et al (2020) 4D printing of materials for the future: opportunities and challenges. Appl Mater Today 18:100490. https://doi.org/10.1016/j.apmt.2019.100490

184. Zhao Q, Wang J, Cui H et al (2018) Programmed shape-morphing scaffolds enabling facile 3D endothelialization. Adv Funct Mater 28(29):1801027. https://doi.org/10.1002/adfm.201801027

185. Gong J, Schuurmans CCL, Genderen AMV et al (2020) Complexation-induced resolution enhancement of 3D-printed hydrogel constructs. Nat Commun 11(1):1267. https://doi.org/1 0.1038/s41467-020-14997-4

186. Pei E, Loh GH (2018) Technological considerations for 4D printing: an overview. Prog Addit Manuf 3(1):95-107. https://doi.org/ 10.1007/s40964-018-0047-1

187. Murata D, Arai K, Nakayama K (2020) Scaffold-free bio-3D printing using spheroids as "bio-inks" for tissue (re-)construction and drug response tests. Adv Healthc Mater 9(15):1901831. https://doi.org/10.1002/adhm.201901831

188. Homan KA, Gupta N, Kroll KT et al (2019) Flow-enhanced vascularization and maturation of kidney organoids in vitro. Nat Methods 16(3):255-262. https://doi.org/10.1038/s41592-019-03 25-y 